\title{
CONTRIBUCIÓN AL CONOCIMIENTO DEL GÉNERO ERYNGIUM (APIACEAE) EN EL ESTADO DE MICHOACÁN, MÉXICO*
}

\author{
IGNACIO GARCÍA-RUIZ \\ Instituto Politécnico Nacional, Centro Interdisciplinario de \\ Investigación para el Desarrollo Integral Regional, \\ Unidad Michoacán, Justo Sierra 28, Apdo. postal 109, \\ 59510 Jiquilpan, Michoacán, México. \\ igarciar@ipn.mx
}

\begin{abstract}
RESUMEN
Eryngium es uno de los géneros más extensos y con mayores dificultades taxonómicas entre las Apiaceae. El grupo incluye de 230 a 250 especies distribuidas en las regiones templadas y tropicales del planeta. Para México se han registrado alrededor de 60 especies, 21 de ellas existen en el estado de Michoacán. Éstas se distribuyen en cinco tipos de vegetación, pero principalmente lo hacen en el pastizal, en bosques de pino-encino y de coníferas. Se incluye una clave para la determinación de las especies citadas.
\end{abstract}

Palabras clave: Apiaceae, Eryngium, hierba del sapo, México, Michoacán, taxonomía.

\begin{abstract}
Eryngium is one of the largest and taxonomically most difficult genera of Apiaceae. It includes from 230 to 250 species, distributed chiefly in temperate tropical regions on the planet. Mexico accounts for about 60 species and there are 21 species of Eryngium in Michoacán State. These species grow in five types of vegetation but mostly in the grassland, and inside pine-oak and conifer forests. A key for species identification is included.
\end{abstract}

Key words: Apiaceae, Eryngium, hierba del sapo, Mexico, Michoacán, taxonomy.

* En memoria de Lincoln Constance (1909-2001). 


\section{INTRODUCCIÓN}

El género Eryngium L. pertenece a la subfamilia Saniculoideae Drude, de la familia Apiaceae Lindley, también conocida como Umbelliferae Juss. Agrupa entre 230 y 250 especies distribuidas en las regiones templadas y tropicales de nuestro planeta (Mabberley, 1997). Sus componentes se distribuyen desigualmente entre y dentro de los hemisferios oriental y occidental. En cada hemisferio se reconocen dos centros de diversidad: el oeste de la región del Mediterráneo y el suroeste de Asia, y la zona centro-occidente de México y centro-oriente de Sudamérica (Turmel, 1948, 1949). Cerca de dos tercios de las especies de Eryngium crecen en el norte, centro y sur de América (Calviño et al., 2008).

En el género se incluyen plantas herbáceas bianuales o perennes, caulescentes o acaulescentes, usualmente glabras y erectas. Tienen raíces fuertes o raicillas fibrosas. Las hojas son simples, lobadas o espinoso-dentadas a lineares, de venación variable, desde reticuladas hasta paralelinervias y con aspecto semejante al de algunas monocotiledóneas. Las flores se encuentran dispuestas en cabezuelas bracteadas, el cáliz generalmente está mejor desarrollado que la corola, los pétalos son de color blanco a púrpura y sésiles. El fruto es globoso u ovoide, cubierto con escamas o tubérculos (Mathias y Constance, 1941). Eryngium es fácilmente distinguible de otros miembros de las Apiaceae por sus inflorescencias capitadas y por tener una sola bractéola por flor. Sin embargo, el género es morfológicamente muy variable. Algunas plantas son postradas o de sólo unos pocos centímetros de alto, otras son erectas y de hasta $3 \mathrm{~m}$ de alto (Calviño et al., 2008). En general la polinización es entomófila.

Varias especies de Eryngium son comestibles o se cultivan como ornato (Heywood, 1978). De otras se aprovechan las raíces en confitería. También las hay medicinales, utilizadas como tónicos, y las hojas de algunas otras son fuente de fibra (Mabberley, 1997).

El género presenta patrones complejos de distribución y se requiere de estudios adicionales para un tratado taxonómico y ecológico. Las relaciones entre los taxones del Nuevo y Viejo mundo no han sido suficientemente investigadas; sólo hasta hace poco tiempo se ha iniciado el estudio de los americanos con material apropiado. Se conocen muchas especies poliploides y se ha sugerido una relación entre la presencia de estas últimas y ciertos patrones de distribución (Mathias, 1965).

Citológicamente, el número básico de cromosomas es $x=8$, pero también los hay menores $(x=6$ o 7) y las variaciones en niveles de ploidía son muy amplias (Calviño et al., 2008); así para el subgénero Monocotyloidea se reportan $x=16,24$, 32, 40 y 48, acorde con Bell y Constance (1966) y Constance et al. (1971, 1976). La 
distribución de los niveles de ploidía puede ser interpretada como evidencia de un origen Mediterráneo/África del Norte para el clado del Nuevo Mundo (Kadereit et al., 2008). Estos mismos autores propusieron una hipótesis sobre la génesis de las especies mexicanas. De acuerdo con la misma, los representantes diploides de $\mathrm{Mo}$ nocotyloidea crecen en el sur de Brasil, norte de Argentina, Uruguay y Paraguay, mientras que los poliploides del mismo subgénero se distribuyen desde los Andes hacia el norte con un centro de diversidad en México y se extienden hasta el oeste de Estados Unidos de América (Kadereit et al., 2008).

El trabajo de Wolff (1913) sobre Eryngium es el más completo y al que se hace referencia de manera obligada. Agrupó a las especies en 34 secciones y 26 subsecciones. El mismo autor reconoció dos principales conjuntos informales: las gerontogeae y las americano australianas, el primer grupo con 12 secciones del Viejo Mundo y el último con 22 secciones para América y Australia (Calviño et al., 2008). Una propuesta más reciente de clasificación con base en caracteres morfológicos fue planteada por Wörz (2005). Sin embargo, ésta no define vínculos de filogenia ni resuelve problemas de relaciones infragenéricas (Calviño y Downie, 2007).

Con respecto a la historia evolutiva de Eryngium, muchos especialistas coinciden en que las especies americanas se originaron de antecesoras del Viejo Mundo. También consideran que el centro de procedencia del género es el suroeste de Asia. Sin embargo, análisis recientes indican un origen en la porción occidental de la región del Mediterráneo (Calviño et al., 2008; Kadereit et al., 2008). Con base en estudios moleculares de ADN de cloroplasto, se confirma la monofilia de Eryngium y se revela una relación de grupo hermano con el género Sanicula L. (Calviño y Downie, 2007). Asimismo un análisis del ADN de cloroplasto apoya la idea de que las especies mexicanas provienen de antecesores del oriente de Estados Unidos de América (Calviño et al., 2008).

En América, Eryngium se desarrolla en varios hábitats entre los cuales destacan lugares pantanosos, bosques, así como zonas abiertas con pastizal. Sus especies crecen en el oeste, centro y sureste de Estados Unidos de América y hacia el sur a través de México, las Antillas, América Central, y norte de Sudamérica (Perú, Ecuador, Venezuela), a lo largo de los Andes y Bolivia hasta Brasil, Paraguay, Uruguay y el norte y centro de Argentina (Calviño et al., 2008).

El objetivo de este trabajo es dar a conocer los representantes de Eryngium que prosperan en Michoacán.

Conocimiento taxonómico

Varios estudios florísticos han registrado representantes de Eryngium para Michoacán. Coulter y Rose (1900) enlistaron 22 especies de México y reconocie- 
ron la presencia de E. spiculosum Hemsl. en el estado. Wolff (1913) mencionó a $E$. beecheyanum Hook. \& Arn., E. carlinae Delar. y E. spiculosum para el mismo. Por su parte Mathias y Constance $(1941,1945)$ registraron a Eryngium beecheyanum, E. cervantesii Delar., E. gracile Delar. y E. globosum Hemsl. Leavenworth (1946) citó del Cerro de Tancítaro a E. bromeliaefolium Delar. y E. carlinae. Hiroe (1979) consignó 37 especies para México y cuatro para Michoacán: E. cymosum Delar., $E$. beecheyanum, E. gracile y E. cervantesii. Por su parte, Martínez y Matuda (1979) reportaron 16 especies en la Flora del Estado de México, dos de las cuales están presentes en Michoacán: E. beecheyanum y E. gracile. Constance (1980) agregó a $E$. mexiae Constance, para la flora de esta región. Asimismo Rzedowski y Rzedowski (2001) consideraron que E. alternatum Coult. \& Rose, E. cervantesii y E. subacaule Cav. se encuentran presentes en la entidad. Por su parte, L. Constance (com. pers. 1988 ) listó para la misma16 especies: E. alternatum, E. beecheyanum, E. bonplandii Delar., E. carlinae, E. cervantesii, E. cymosum, E. ghiesbreghtii Decaisne, E. gracile, E. longifolium Cav., E. mexiae, E. mexicanum S. Wats., E. phyteumae Delar., E. proteaeflorum Delar., E. serratum Cav., E. spiculosum y E. subacaule. García et al. (1991), en su estudio florístico del noroeste de Michoacán registraron siete especies: E. alternatum, E. beecheyanum, E. bonplandii, E. carlinae , E. ghiesbreghtii, E. gracile y E. mexiae. Finalmente, Rodríguez-Jiménez y Espinosa-Garduño (1996) enlistaron 29 especies de Eryngium para el estado.

Área de estudio

El estado de Michoacán está situado en la porción centro-oeste de México, entre las coordenadas $20^{\circ} 23^{\prime} 27^{\prime \prime}-17^{\circ} 53^{\prime} 50^{\prime \prime}$ de latitud norte y $100^{\circ} 03^{\prime} 32^{\prime \prime}-103^{\circ} 44^{\prime} 49^{\prime \prime}$ de longitud oeste. Colinda al norte con Jalisco y Guanajuato; al noreste con Querétaro; al este con el Estado de México y Guerrero; al oeste con Jalisco y Colima; y al sur con el Océano Pacífico (Correa, 1974; Guevara, 1989) (Fig. 1).

Fisiografía. Dentro de esta entidad se presentan cuatro grandes unidades fisiográficas: El Eje Volcánico Transversal, la Sierra Madre del Sur, la Altiplanicie Mexicana y la Depresión del Balsas. De cada una de éstas Michoacán participa sólo de manera parcial (Guevara, 1989).

En cuanto a regiones naturales, se ha seguido el punto de vista de Miramontes (1936) que incluye cinco (Fig. 2):

1. Región de los Valles y Ciénagas. Corresponde a una faja de terreno que se encuentra en la parte norte del estado, en la que existen importantes planicies y valles. Está incluida en el Eje Volcánico Transversal. 


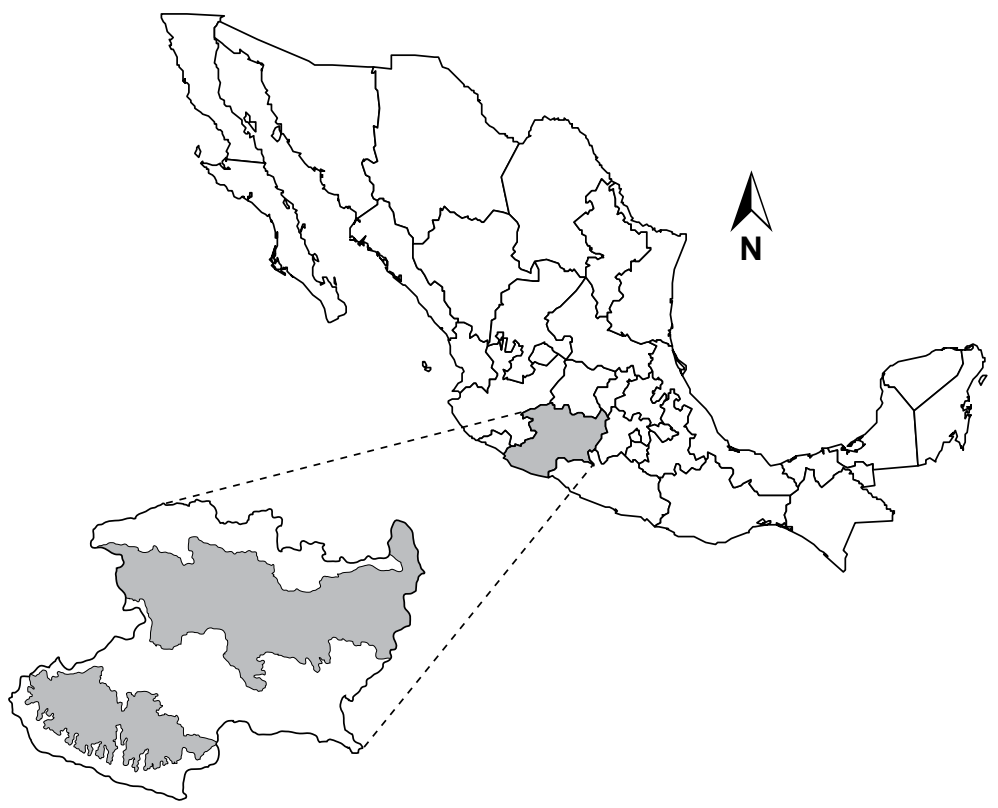

Fig. 1. México y el estado de Michoacán, ampliado.

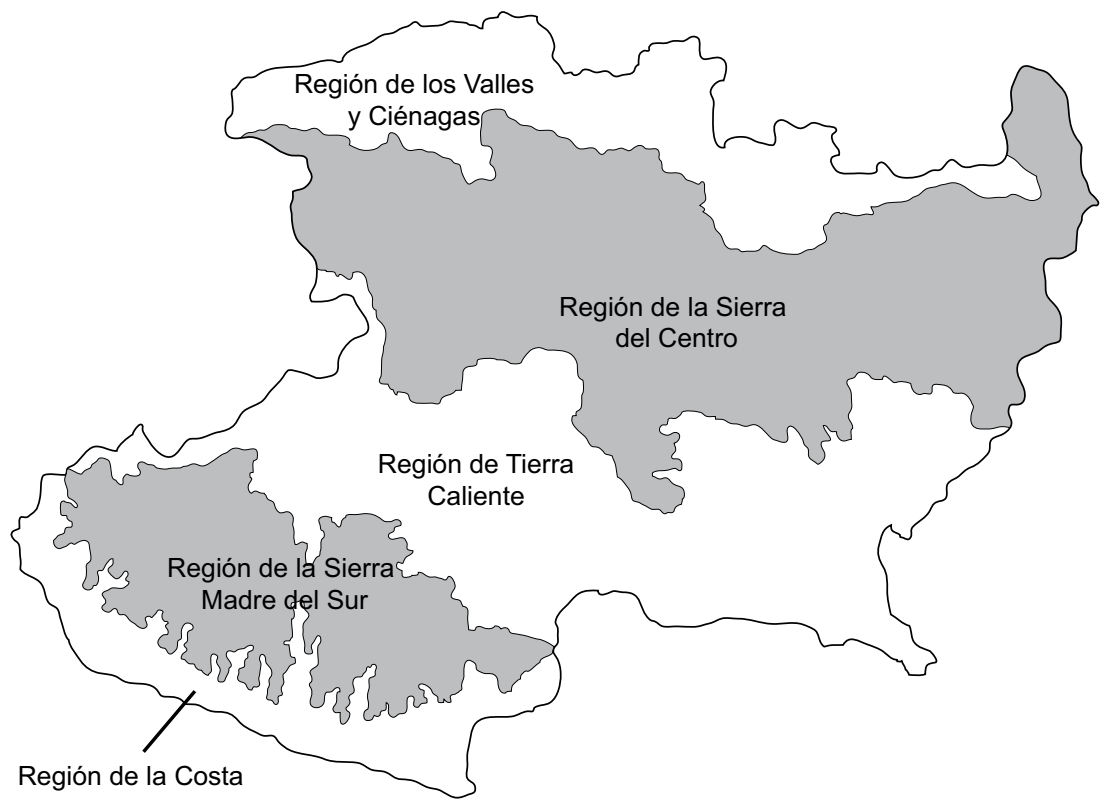

Fig. 2. Estado de Michoacán con las regiones naturales planteadas por Miramontes (1936). 
2. Región de la Sierra del Centro. Es la cadena montañosa (Eje Volcánico Transversal) que atraviesa el estado en su parte central en dirección este-oeste. También incluye a algunos valles.

3. Región de la Tierra Caliente. Representa la región comprendida entre el Eje Volcánico Transversal y la Sierra Madre del Sur.

4. Sierra Madre del Sur. Es una cadena montañosa paralela al Océano Pacífico, con una topografía muy accidentada en los municipios de Arteaga, Aquila, Aguililla, Coalcomán, Tumbiscatío de Ruiz y Villa Victoria.

5. Región de la Costa. Constituye la faja de terreno que se encuentra entre la Sierra Madre del Sur y el Océano Pacífico.

Hidrografía. Tres grandes sistemas hidrográficos denominados por su posición geográfica del norte, centro y sur, además del sistema fluvial costero, son los que se localizan en la entidad (Guevara, 1989). Michoacán está drenado por los ríos Lerma y Balsas, principalmente. Por otra parte, los ríos de la región de Arteaga y Coalcomán desaguan en la vertiente del Pacífico de la Sierra Madre del Sur desembocando directamente en el Océano Pacífico. Por último queda la red interna de los lagos endorreicos Cuitzeo, Pátzcuaro y Zirahuén.

Clima. Los tipos climáticos que predominan en Michoacán de acuerdo con el sistema de clasificación de Köppen modificado por García (1988), son:

Awg. Clima tropical lluvioso, con lluvias en verano. En la región de la Costa y porciones de mayor altitud de la Depresión del Balsas, así como en las estribaciones de la Sierra de Coalcomán.

BSwg. Clima seco estepario cálido con lluvia escasa que predomina en verano; la temperatura media anual es superior a $18{ }^{\circ} \mathrm{C}$ y la media mensual de algunos meses es inferior a $18{ }^{\circ} \mathrm{C}$. Característico de las áreas de menor altitud en la cuenca baja del Río Balsas.

Cwag. Clima templado subhúmedo con lluvias en verano, temperatura media del mes más caliente mayor de $22{ }^{\circ} \mathrm{C}$. Se distribuye en la mayor parte de la Región de los Valles y Ciénagas, en la Sierra de Coalcomán y Arteaga y zonas de transición entre la Sierra del Centro y la Cuenca del Balsas-Tepalcatepec.

Cwbg. Clima templado subhúmedo, con lluvias en verano, la temperatura media del mes más cálido es inferior a $22{ }^{\circ} \mathrm{C}$. Se extiende en la mayor parte de la Sierra del Centro y serranías aisladas de la Región de los Valles del Norte.

Cwf. Clima templado con lluvias todo el año y una época más seca en el invierno. Corresponde a las cumbres más altas de la Sierra del Centro (Sierras de 
Tancítaro, Paracho, Patamban en el oeste; las Sierras de Tlapujahua y Angangueo en el oriente, así como en las Sierras de Acuitzio, Nahuatzen y Pátzcuaro hacia el Centro (Guevara, 1989).

Suelo. De acuerdo con la clasificación de la Organización de las Naciones Unidas para la Alimentación y la Agricultura (FAO), en Michoacán se presentan los siguientes tipos:

Andosol. Abundan en la Sierra del Centro y las estribaciones de la Sierra de Coalcomán.

Fluvisol. Se localizan en las vegas de los ríos y arroyos, en llanuras aluviales y áreas de pie de monte de regiones secas.

Litosol. Se localizan principalmente en la Sierra del Centro y la Sierra de Coalcomán.

Regosol. Tienen una distribución en la Sierra del Centro y la Sierra de Coalcomán.

Rendzina. Se localizan principalmente en los municipios de La Huacana, Arteaga, Churumuco, Huetamo y San Lucas en la Depresión del Balsas.

Vertisol. Predominan en la región de los Valles y Ciénagas, así como en el plan de Tierra Caliente en la cuenca del Tepalcatepec (Guevara, 1989).

\section{MATERIALES Y MÉTODOS}

En el presente trabajo se incluyeron tres fases: compilación bibliográfica, revisión de herbarios y colecta de material botánico. La primera y segunda se llevaron a cabo simultáneamente mediante la consulta de bibliotecas y de los principales herbarios del país, así de los regionales y uno de Estados Unidos de América. Los herbarios consultados fueron:

Herbario de la Universidad Autónoma de Chapingo (CHAP).

Herbario del Centro Interdisciplinario de Investigación para el Desarrollo Integral Regional Unidad Michoacán del Instituto Politécnico Nacional (CIMI).

Herbario de la Escuela de Biología de la Universidad Michoacana de San Nicolás de Hidalgo (EBUM).

Herbario de la Escuela Nacional de Ciencias Biológicas del Instituto Politécnico Nacional (ENCB).

Herbario del Instituto de Ecología, A.C. Centro Regional del Bajío (IEB). 
Herbario del Instituto Nacional de Investigaciones Forestales (INIF). Herbario Nacional, Universidad Nacional Autónoma de México (MEXU). Herbario Jepson, Universidad de California, Berkeley (UC).

La tercera fase comprendió 30 viajes de recolección, considerando la visita no sólo a las localidades referidas en la literatura y etiquetas de los ejemplares revisados, sino también a otros sitios poco frecuentados por los colectores botánicos.

El material recolectado se encuentra depositado en los herbarios CIMI, ENCB, IEB, MEXU, UC y UCR y se enviará adicionalmente a algunos otros como EBUM, IBUG, MICH, XAL.

\section{RESULTADOS}

Como resultado de la revisión de herbario y las recolecciones realizadas en el estado de Michoacán, se reconocen 21 especies de Eryngium.

\section{Eryngium L.}

Hierbas perennes o bianuales, robustas a delgadas, erectas a postradas y reptantes, esencialmente glabras y generalmente espinosas, con raíces axonomorfas, fasciculares, vitas o conductos de aceite inconspicuos. Hojas principalmente basales o alternas, con o sin pecíolo evidente, generalmente coriáceas, pinnado o palmado-lobadas o divididas a simples y enteras, con frecuencia espinosas o ciliadas, la nervación paralela o reticulada; pecíolos envainadores, a veces septados y/o sin lámina. Inflorescencia capitada, las cabezuelas solitarias a numerosas en cimas, racimos o panículas; involucro de 1 o rara vez más series de brácteas enteras a lobadas. Flores todas bisexuales, sésiles o a veces pediceladas, con bractéolas individuales del involucelo subyacentes, enteras o lobadas, a menudo con 1 o más bractéolas terminales salientes a manera de coma; sépalos conspicuos, persistentes; pétalos ovados a oblongos, blancos a purpúreos, con ápice reflexo, entero o dividido, más corto; estilos más largos o más cortos que el cáliz, el estilopodio ausente, carpóforo ausente. Frutos en forma de esquizocarpos, globosos a ovoides, algo aplanados lateralmente, con la cara comisural amplia, costillas ausentes o poco aparentes y cubiertos por tubérculos o escamas, o las superficies lisas; formados por dos mericarpos redondeados o aplanados dorsalmente (Fig. 3). 

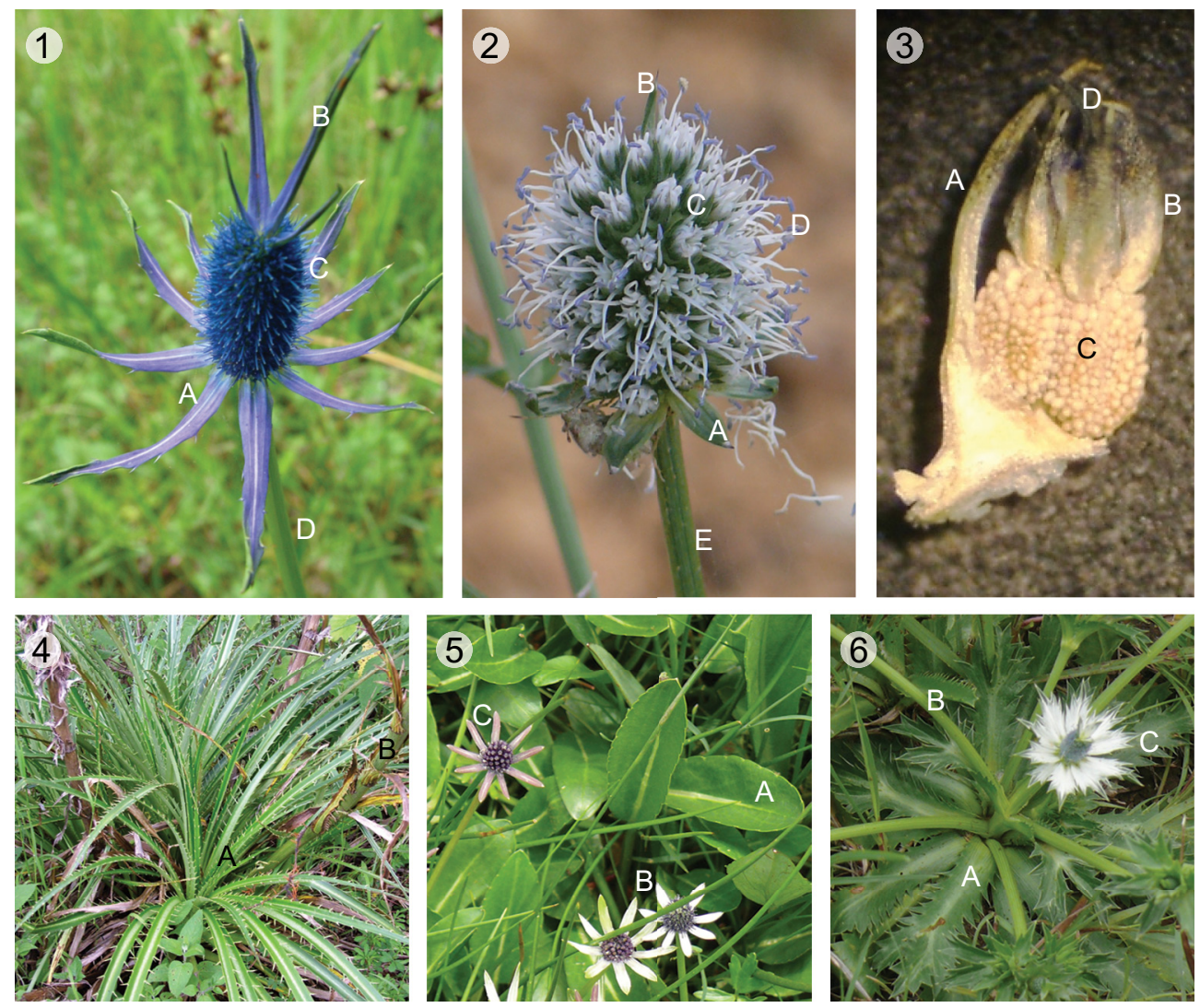

Fig. 3. Rasgos morfológicos de algunas especies de Eryngium. 1. Inflorescencia de E. phyteumae. A. bráctea; B. coma; C. estilos; D. pedúnculo de la inflorescencia. 2. Inflorescencia de E. serratum. A. bráctea; B. coma poco conspicuo; C. flor; D. estambres; E. pedúnculo. 3. Fruto de E. beecheyanum. A. bractéola; B. sépalos; C. ovario con papilas; D. estilos. 4. Hojas basales en roseta de E. alternatum. A. hojas de venación paralela y con espinas; B. tallo floral. 5. E. subacaule. A. hojas de nervación reticulada; B. pecíolo; C. inflorescencia sin coma. 6. E. carlinae. A. hojas postradas setoso-serradas a pinnatífidas; B. pedúnculo de la inflorescencia; C. inflorescencia con coma.

Clave para determinar las especies de Eryngium de Michoacán

1 Hojas basales con pecíolo evidente, la lámina con venación reticulada; frutos \pm rollizos, cubiertos por escamas o papilas.

2 Plantas postradas; nudos del tallo con raíces; hojas fasciculadas ... E. cervantesii 
2 Plantas por lo general erectas o extendidas, a veces postradas (en E. carlinae); hojas no fasciculadas.

3 Plantas ligeramente suculentas, acuáticas o creciendo en lugares de suelo húmedo; pecíolos huecos y usualmente septados.

4 Cabezuelas sin coma; hojas con nervaduras palmado-reticuladas .... E. subacaule

4 Cabezuelas con coma conspicuo; hojas con nervaduras pinnadoreticuladas.

5 Inflorescencia poco ramificada; brácteas del involucro 6 a 10; coma formado por varias (3 a 5) bractéolas subiguales ........ E. phyteumae

5 Inflorescencia cimoso-trifurcada; brácteas del involucro 8 a 12(15); coma filiforme, entero o partido, formado de una sola bractéola .......

E. mexicanum

3 Plantas no suculentas, terrestres; pecíolos nunca huecos ni septados.

6 Brácteas involucrales claramente bicoloras, usualmente verdes en el envés y azules o plateadas en el haz.

7 Plantas evidentemente espinosas; cabezuelas con un coma conspicuo.

8 Hojas basales y caulinares setoso-serradas a subpinnatífidas; cabezuelas ovoide-cilíndricas, de 6 a $10 \mathrm{~mm}$ de largo; brácteas de 8 a $20 \mathrm{~mm}$ de largo.

9 Plantas bajas y postradas o ascendentes, perennes, acaules o cortamente caulescentes; brácteas de 8 a $20 \mathrm{~mm}$ de largo; con escamas aplanadas en los ángulos del fruto, las caras con papilas cónicas; estilos más cortos que los sépalos

E. carlinae

9 Plantas no postradas, erectas, bianuales, caulescentes; brácteas de 8 a $15 \mathrm{~mm}$ de largo; papilas abundantes en las caras y ángulos del fruto; estilos tan largos o un poco más largos que los sépalos

E. beecheyanum

8 Hojas basales y caulinares profundamente espinoso-serradas a bipinnatisectas o pinnatifidas; cabezuelas ovoides, de 7 a $15 \mathrm{~mm}$ de largo; brácteas de 12 a $25 \mathrm{~mm}$ de largo ...... E. heterophyllum

7 Plantas poco a escasamente espinosas; cabezuelas sin coma.

10 Hojas arregladas en espiral, redondeadas en la base, nervaduras pinnadamente reticuladas ..................................... E. bonplandii

10 Hojas dísticas, cordadas o caudadas en la base, nervaduras palmado-reticuladas. 
11 Hojas agudas, triangulares a ovado-cordadas, generalmente caudadas en la base, finamente espinuloso-serradas; brácteas 6 a 8 E. ghiesbreghtii

11 Hojas obtusas, ovadas a oblongas, cordadas a redondeadas en la base, crenadas o profundamente crenado-serradas; brácteas 8 a 12 E. gracile

6 Brácteas involucrales no bicoloras, verdes o blanquecinas o débilmente azuladas.

12 Cabezuelas subglobosas a ovoide-cilíndricas; sin coma o éste poco evidente

E. serratum

12 Cabezuelas más largas que anchas; con un coma evidente.

13 Plantas densamente espinosas; flores sésiles; fruto con escamas aplanadas o papilas bajas y cónicas.

14 Brácteas involucrales trifurcadas a pinnatífidas, tan largas o más cortas que la cabezuela; cabezuelas cilíndricas

E. comosum

14 Brácteas involucrales enteras a espinoso-dentadas, usualmente más largas que la cabezuela; cabezuelas ovoide-cilíndricas a ovoides.

15 Plantas bianuales, con un fascículo de raíces fibrosas; cabezuelas ovoide-cilíndricas, de 6 a $10 \mathrm{~mm}$ de largo; brácteas de 8 a $15 \mathrm{~mm}$ de largo; papilas similares en las caras y ángulos del fruto E. beecheyanum

15 Plantas perennes, con una raíz vigorosa; cabezuelas ovoides, de 7 a $15 \mathrm{~mm}$ de largo; brácteas de 12 a $25 \mathrm{~mm}$ de largo; escamas y papilas del fruto desiguales

E. heterophyllum

13 Plantas escasamente espinosas; cabezuelas globoso-ovoides, casi tan largas como anchas; flores pediceladas; frutos densamente cubiertos con escamas y papilas alargadas y setiformes

E. spiculosum

1 Hojas basales sin pecíolo evidente, con venación paralela; frutos aplanados, con el margen alado o con escamas aplanadas.

16 Brácteas involucrales imbricadas, en 2 o más series; cabezuelas grandes ( 3 a $7 \mathrm{~cm}$ de largo).

17 Brácteas del involucro biseriadas, enteras; tallo de más de $1.5 \mathrm{~m}$ de alto; inflorescencia con numerosas cabezuelas E. alternatum 
17 Brácteas del involucro multiseriadas, enteras o espinoso-dentadas; tallo hasta de $1.2 \mathrm{~m}$ de alto; inflorescencia con pocas cabezuelas o éstas solitarias.

18 Cabezuela ovoide-cilíndrica, de 2 a 6(7) $\mathrm{cm}$ de largo y de 1.5 a 3(4) $\mathrm{cm}$ de ancho E. proteaeflorum

18 Cabezuela ovoide, de 1 a 2.5(4) $\mathrm{cm}$ de largo y de 1 a 1.5(2.5) cm de ancho E. monocephalum

16 Brácteas involucrales no imbricadas, en una serie; cabezuelas generalmente menores de $3 \mathrm{~cm}$ de largo.

19 Márgenes de las hojas débilmente espinosos y sin espínulas axilares; brácteas comúnmente mucho más cortas que la cabezuela.

20 Hojas ligeramente espinosas; brácteas 6 a 8; cabezuelas verdosas, ovoide-cilíndricas, de 8 a $15 \mathrm{~mm}$ de largo E. longifolium

20 Hojas enteras o casi enteras; brácteas 8 a 12; cabezuelas azules, ovoideoblongas, de 15 a $25 \mathrm{~mm}$ de largo E. sparganophyllum

19 Márgenes de las hojas firmemente espinoso-lobados y comúnmente con espínulas axilares; brácteas más largas que las cabezuelas.

21 Cabezuelas ovoides a oblongas, azules o purpúreas E. columnare

21 Cabezuelas ovoides a semiesféricas, blanco-verdosas.

22 Hojas \pm glaucas y usualmente dísticas; cabezuelas ovoides a globosas; superficie dorsal del fruto desnuda, con vesículas cerca de la base del cáliz E. mexiae

22 Hojas usualmente verdes, arregladas en espiral; cabezuelas globosas a hemisféricas; superficie dorsal del fruto algo escamosa o vesiculada sobre todo en las costillas laterales E. cymosum

Sinopsis de las especies

1. Eryngium alternatum Coult. \& Rose, Contr. U.S. Nat. Herb. 3: 298. 1895. E. grande Hemsl. \& Rose. 1905.

Hierba perenne, glabra, a veces algo leñosa en la base, erecta; tallo solitario o ramificado, de 1.5 a $3 \mathrm{~m}$ de alto; hojas basales linear-lanceoladas, de (40)50 a 80(100) $\mathrm{cm}$ de largo, de 1 a $2.5 \mathrm{~cm}$ de ancho, borde espinoso-aserrado con los dientes rígidos, extendidos o ascendentes, de 5 a 20(25) $\mathrm{mm}$ de largo, ápice acuminado, nervación paralela; hojas superiores alternas pero las más próximas al ápice opuestas; inflorescencia de $50 \mathrm{~cm}$ o más de largo, más bien estrecha, con las ramas ascendentes y 
a menudo alternas; cabezuelas ovoides o cilíndricas, de 1 a 3(4) $\mathrm{cm}$ de largo y de 1 a $2.5 \mathrm{~cm}$ de diámetro, con numerosas flores; brácteas del involucro 15 a 30, lanceoladas, biseriadas, de 1.5 a $4 \mathrm{~cm}$ de largo y de 2 a $4 \mathrm{~mm}$ de ancho, margen entero, decurrentes sobre el pedúnculo; bractéolas lanceoladas, de 4 a $7 \mathrm{~mm}$ de largo, espinosas en la punta, de margen entero; coma ausente; sépalos ovados, agudos, de alrededor de $2 \mathrm{~mm}$ de largo, espinosos en la punta, de margen entero; pétalos blanquecinos; estilos 3 o 4 veces más largos que los sépalos; fruto de 3 a $4 \mathrm{~mm}$ de largo y de 2 $\mathrm{mm}$ de ancho, liso o con escamas en la base del cáliz, las laterales conspicuas y prolongándose hacia abajo en alas angostas, con frecuencia 1 o 2 escamas intermedias entre las laterales.

Habitat, fenología y distribución geográfica. Eryngium alternatum crece en el pastizal, sotobosque y claros del bosque de coníferas, entre los 2750-3400 m de altitud. Florece de abril a mayo y fructifica de julio a noviembre. Se conoce su distribución en el Estado de México, Guanajuato, Hidalgo, Jalisco, Michoacán, Morelos, Oaxaca y Puebla. En Michoacán se registra de la Sierra del Centro.

Discusión. De la región oriente del estado se reporta con el nombre local de carricillo. Eryngium alternatum es morfológicamente similar a E. monocephalum, pero difiere de ésta en que la primera es más alta, sus cabezuelas son varias y de menor tamaño y sus brácteas son enteras.

Ejemplares observados: Municipio de Angangueo: lado norte de Las Papas, 3277 m, I. García y M. García 8366 (CIMI); Las Papas, 3100 m, I. García y M.. García 2014 (CIMI, IEB); límites entre los estados de Michoacán - México, carretera San José del Rincón - Angangueo, 3100 m, I. García y M. García 3237 (CIMI, UC). Municipio de Huiramba: Cerro Burro, 3300 m, J. Rzedowski 41906 (EBUM, ENCB, IEB); Cerro Burro, 3200 m, J. Rzedowski 43783 (ENCB, IEB, UC). Municipio de Nahuatzen: Cerro Pilón, E. García y E. Pérez 3344 (IEB). Municipio de Nuevo Parangaricutiro: San Nicolás, al E del Cerro Tancítaro, 2600 m, I. García y Y. Hernández 3443 (CIMI); cerca del Cerro de las Antenas, 3550 m, I. García y J. A. Machuca 4089 (CIMI). Municipio de Paracho: Cerro Tzucuian, $3100 \mathrm{~m}, X$. Madrigal 12 (ENCB). Municipio de Pátzcuaro: Cerro Burro, 3150 m, H. Díaz 1003 (CIMI, IEB, UC); $18 \mathrm{~km} \mathrm{~S}$ of Pátzcuaro, $8900-9000 \mathrm{ft}, R$. M. King y T. R. Soderstrom 5203 (NY, UC). Municipio de Quiroga: Cerro Tzirate, 3370 m, H. Díaz y $S$. Zamudio 2115 (CIMI, IEB); Cerro Tzirate, H. Díaz y S. Zamudio 2815a (IEB). Municipio de Salvador Escalante: Cerro Burro, 3050 m, J. M. Escobedo 1413 (ENCB, 
IEB, MEXU); Cerro Burro, 3200 m, E. Pérez 39 (IEB). Laguna San Gregorio, 2900 m, I. García y S. Zamudio 2338 A (CIMI, IEB); Municipio de Tangancícuaro: Mesa del Cerro Viejo, 3100 m, F. Takaki sitio 7 (INIF); NW del Cerro de Patamban, 2600 m, I. García y G. Hernández 3698 (CIMI). Municipio de Zamora: Cerro la Beata, $2370 \mathrm{~m}, X$. Madrigal sitio 40-II-2 (INIF). Municipio de Zinapécuaro: NW del Cerro San Andrés, 3000 m, I. García et al. 3660 (CIMI). Municipio de Zitácuaro: $0.4 \mathrm{mi} \mathrm{N}$ of Lengua de Vaca, Hwy $15 \mathrm{~S}$ of Zitácuaro, ca. $9500 \mathrm{ft}, C$. R. Bell y J. A. Duke 16739 (UC); km 30 carretera Zitácuaro - México, 2920 m, R. W. Cruden 1140

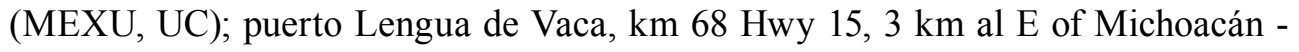
México border, H. Iltis y T. Cochrane 329 (ENCB, IEB); Zitácuaro - Toluca at km 149 on Route 15, 2460 m, B. G. Schubert y M. Sousa 2119 (UC). Sin registro de municipio: media falda del Cerro del Pájaro, 2400 m, A. Mancera y F. Takaki S-11 (INIF).

2. Eryngium beecheyanum Hook. \& Arn., Bot. Beechey Voy. 294. 1840.

E. tenue Hook. \& Arn. 1838. No E. tenue Lam. 1797.

E. cryptanthum Hemsl. 1897.

E. tenuissimum Hemsl. 1899.

E. seleri Wolff 1909.

Hierba bianual, glabra, delgada, caulescente, divaricadamente ramificada; raíces fasciculadas, fibrosas; tallo de 15 a $60 \mathrm{~cm}$ de alto; hojas basales numerosas, rosuladas, oblanceoladas, de 3 a $8 \mathrm{~cm}$ de longitud, largamente cuneadas en la base, ápice obtuso, setoso-serradas a subpinnatifidas, venación pinnadamente reticulada, pecíolos cortos u obsoletos, alados y envainantes en la base, hasta de $1 \mathrm{~cm}$ de largo, mucho más cortos que las láminas; hojas caulinares similares a las basales, setososerradas o superficialmente incisas a pinnatífidas, las superiores palmadamente partidas, sésiles, las cercanas a la inflorescencia opuestas; inflorescencia en forma de cima divaricada, las cabezuelas pequeñas, numerosas, pedunculadas; cabezuelas azules u ocasionalmente blancas, ovoide-cilíndricas, de 6 a $10 \mathrm{~mm}$ de largo y de 5 a $6 \mathrm{~mm}$ de ancho, flores numerosas; brácteas 8 a 12, cartáceas, extendidas, linearlanceoladas, de 8 a $15 \mathrm{~mm}$ de largo y de 2 a $3 \mathrm{~mm}$ de ancho, pungentes, verdes o azulosas abajo y blanco-amarillentas en el haz, con 1 a 3 espinas laterales cortas o enteras, excediendo u ocasionalmente sólo igualando el largo de las cabezuelas; bractéolas subuladas, de 3 a $4 \mathrm{~mm}$ de largo, enteras, curvadas, excediendo el largo del fruto; coma de 1 a 3 bractéolas usualmente enteras, de 2 a $6 \mathrm{~mm}$ de largo, u ocasionalmente obsoletas; sépalos ovados, de cerca de $1 \mathrm{~mm}$ de largo, obtusos, api- 
culados; pétalos obovados, de cerca de $1 \mathrm{~mm}$ de largo; estilos más bien cortos, tan largos o ligeramente excediendo a los sépalos; fruto globoso a elipsoide, de 1 a $2 \mathrm{~mm}$ de largo y $1 \mathrm{~mm}$ de ancho, con abundantes papilas uniformes a subiguales sobre las caras y ángulos.

Habitat, fenología y distribución geográfica. Eryngium beecheyanum crece en el pastizal, bosque tropical caducifolio y bosque de encino-pino, entre los 1500$2550 \mathrm{~m}$ de altitud; también se ha encontrado formando parte de la vegetación ruderal y arvense. Florece de abril a mayo y fructifica de junio a enero. Se conoce de Chiapas, Chihuahua, Estado de México, Jalisco, Michoacán, Oaxaca y Sonora; es citado también de Centroamérica. En Michoacán se registra de la Sierra del Centro y la Sierra Madre del Sur.

Discusión. Esta especie es conocida ampliamente con el nombre común de hierba del sapo. E. beecheyanum es morfológicamente muy parecida a $E$. heterophyllum, sin embargo difiere en que $E$. beecheyanum es bianual, delgada, de menor tamaño, con raíces fibrosas, hojas basales enteras setoso-aserradas a subpinnatifidas y el coma es más reducido. También tiene cierto parecido con individuos de $C$. carlinae en etapas tempranas de su desarrollo, cuando éstos tienen la forma de plantas bajas sin tallo o con tallo corto, con hojas basales postradas, así como con individuos que presentan un largo tallo con inflorescencias ramificadas bien desarrolladas; sin embargo, el tallo en E. beecheyanum es evidentemente menos ramificado, erecto, delgado, las brácteas son menos anchas y los estilos tan largos o más largos que los sépalos.

Ejemplares observados: Municipio de Acuitzio del Canje: Cerro Las Peñitas, 2280 m, H. Díaz 1290 (IEB). Municipio de Ario de Rosales: carretera Ario de Rosales - La Huacana, km 13, 1520 m, J. C. Soto 4458 (ENCB, MEXU). Municipio de Charo: El Álamo, $6 \mathrm{~km}$ al E de El Temascal, carretera Morelia - Mil Cumbres - Ciudad Hidalgo, $2450 \mathrm{~m}, J$. C. Soto 5489 (MEXU); La Polvilla ca. $18 \mathrm{mi}$ of Morelia, $R$. M. King y T. R. Soderstrom 5066 (MEXU, UC). Municipio de Coeneo: $22 \mathrm{~km}$ arriba del Lago de Pátzcuaro NW de Quiroga, H. H. Iltis, R. Koeppen y F. Iltis 532 (UC). Municipio de Cotija: Agua de Maguey, 2200 m, I. García 2201 (CIMI, UC); Agua de Maguey, 2300 m, I. García 3001 (CIMI, UC); Tierras Blancas, 2020 m, I. García 3079 (CIMI). Municipio de Erongarícuaro: Oponguio, 2100 m, H. Díaz y C. Suárez 6342 (CIMI, IEB); $0.5 \mathrm{~km}$ al N de la Hacienda de Cherahuén, $2140 \mathrm{~m}$, A. Espinoza 2315 (IEB). Municipio de Jiquilpan: $1 \mathrm{~km}$ al N de la desviación a Los Tábanos, carretera Jiquilpan - Colima, 1850 m, I. García 2481 (CIMI); 1.5 km de La Jara, 1970 
m, J. L. Villalpando 594 (CIMI, INIF); al NE de Los Tábanos, 1850 m, I. García 8374 (CIMI); Cerro La Viña, aproximadamente $9 \mathrm{~km}$ al SW de Jiquilpan, $2000 \mathrm{~m}$, I. García 2968 (CIMI, UC); Cerro Santa María, 8-10 km al SW de Jiquilpan y $5 \mathrm{~km}$ al NE de Quitupan, 2000 m, C. Feddema 1 (ENCB, UC). Municipio de Los Reyes: aproximadamente $1 \mathrm{~km}$ carretera Los Reyes - Zamora, $1480 \mathrm{~m}$, I. García y Y. Hernández 3510 (CIMI); lado N-NE de la Barranca Chorros del Varal, 1000 m, I. García 6724 (CIMI); Sicuicho, 2360 m, M. T. Martínez 53 (IEB); km 48.5 carretera Zamora - Los Reyes, 1500 m, I. García 2552 (CIMI, ENCB, UC). Municipio de Maravatío: aproximadamente $2 \mathrm{~km}$ al NW de Maravatío, 2020 m, I. García y Y. Hernández 3539 (CIMI, IEB); Cerro Las Palomas al S de Santiaguito, 2200 m, H. Díaz 4296 (IEB). Municipio de Marcos Castellanos: Agua Caliente, 1750 m, I. García 2050 (CIMI, IEB); Agua Caliente, 1750 m, I. García 2571 (CIMI, UC); La Arena, al SW de Jiquilpan, 2000 m, I. García 2855 (CIMI, UC); lado oriente de La Arena, 2100 m, I. García 8370 (CIMI). Municipio de Morelia: $1 \mathrm{~km}$ al W de puerto Pascual Ortiz Rubio, 21 $\mathrm{km}$ al E de Morelia, sobre carretera 15, $6000 \mathrm{ft}$., R. Ornduff 8889 (ENCB, UC); 11 mi SW de Morelia, J. T. Waterfall 16447 (UC); 26 mi, E de Morelia carretera 15 entre Morelia y Ciudad Hidalgo, G. L. Webster y G. J. Breckon 16146 (UC); cerca del Puerto de los Copales $8 \mathrm{~km}$ al E de Morelia, carretera a Guadalajara, $2050 \mathrm{~m}, J$. C. Soto 2379 (ENCB); Cerro de las Tetillas del Quinceo, 2350 m, V. M. Huerta 177 (EBUM); entre Huaniqueo y Teremendo al N-NW de Morelia, 1980 m, I. García 3224 (CIMI, UC); entre Teremendo y Tiristirán, 2000 m, I. García 3225 (CIMI); Loma Santa María, $2000 \mathrm{~m}, G$. Arsène 3066 (MEXU); km 34.6 carretera 15 Morelia - Quiroga, $B$. G. Schubert y M. Sousa 2110 (UC); Loma Santa María, 2000 m, I. García 3226 (CIMI, UC), presa de Loma Caliente, 2200 m, E. García 3831 (EBUM, IEB). Municipio de Ocampo: $2 \mathrm{~km}$ al E de Ocampo, camino al Rosario, $2900 \mathrm{~m}, R$. Torres y M. Ramírez 13570 (IEB). Municipio de Paracho: $2 \mathrm{~km}$ al SW de Paracho, 2200 m, I. García 2399 (CIMI, IEB, UC); carretera no. 39, $13.8 \mathrm{mi}, \mathrm{S}$ de Carapan, C. R. Bell y J. A. Duke 16695 (UC); km 46.5 carretera Carapan - Uruapan al S de Paracho, 2350 m, I. García 3014 (CIMI, UC); NE Mesa de Cherán - Atzicurín, 2250 m, M. Pérez 292 (ENCB, IEB). Municipio de Pátzcuaro: $7 \mathrm{~km}$ al S de Pátzcuaro, carretera a Opopeo, 2340 m, J. Espinosa 1983 (IEB); $18 \mathrm{~km}$ al S de Pátzcuaro, R. M. King y T. R. Soderstrom 5192 (MEXU, UC); entrada a Pátzcuaro Motel Tolimán, C. R. Bell y J. A. Duke 16705 (UC); Lago de Pátzcuaro, 2135 m, L. E. Detling 8490 (ENCB); Pátzcuaro, sin nombre de colector 1235 (MEXU); wet soil, Lake Pátzcuaro, C. G. Pringle 4120 (MEXU, UC). Municipio de Peribán de Ramos: Cerro Tancítaro, 6-7 km al S de Peribán, R. McVaugh 24845 (UC). Municipio de Quiroga: Cerro El Tzirate, C. López 1091 (EBUM). Municipio de Salvador Escalante: Zirahuén, 2150 m, J. M. Escobedo 53 
(CHAP, ENCB, IEB). Municipio de Senguio: $1 \mathrm{~km}$ al SW de Pichardo, $2500 \mathrm{~m}, I$. García 2511 (CIMI, UC). Municipio de Tancítaro: Barranca del Agua al N de Zirimondiro, I. García et al. 4236 (CIMI); Tancítaro, 2200 m, G. B. Hinton 15674 (ENCB, UC). Municipio de Tangancícuaro: base del Cerro Patamban, $2300 \mathrm{~m}$, J. Rzedowski y R. McVaugh 644 (ENCB); entre Guarachanillo y Patamban, 2200 m, I. García 2126 (CIMI). Municipio de Tingambato: $8 \mathrm{~km}$ al N de Aristeo, 1700-1800 m, A. Martínez 474 (ENCB). Municipio de Tlalpujahua: SE de San Francisco de Los Reyes, 2500 m, I. García y Y. Hernández 3526 (CIMI). Municipio de Tlazazalca: Cerro de la Cruz, 2000 m, E. Pérez 1073 (EBUM, IEB); Cerro de la Cruz, 1800 m, E. Pérez y E. García 1335 (IEB). Municipio de Tzintzuntzan: Cerro Carichuato, $2250 \mathrm{~m}, R$. Olivo 74 (IEB); Cerro Tarianqueri, $2160 \mathrm{~m}, R$. Olivo 114 (IEB). Municipio de Uruapan: $1.8 \mathrm{mi}$ al oeste del pueblo Paricutín, C. R. Bell y J. A. Duke 16690 (UC); $20 \mathrm{~km} \mathrm{~S}$ of Cherán, Carapan - Uruapan, $R$. Ornduff 8590 (ENCB, MEXU, UC); 6-7 km al N de Uruapan, 1700 m, J. V. A. Dieterle 4399 (ENCB); Barranca del Cupatitzio, 1810 m, X. Madrigal 2963 (INIF, MEXU); Capacuaro hacia Paracho, C. Illsley 965 (IEB); Estación Coru, C. G. Pringle 13526 (UC); km 52, carretera Carapan - Uruapan, $2150 \mathrm{~m}$, I. García 2486 (CIMI, UC). Municipio de Villamar: $2 \mathrm{~km}$ al S desviación a Jaripo, 1550 m, I. García 2386 (CIMI). Municipio de Villa Victoria: Joya del Durazno CFE Barranca Cupatitzio, 1810 m, X. Madrigal 2963 (INIF); La Yerbabuena, 1400 m, H. Díaz y E. Pérez 6184 (CIMI, IEB). Municipio de Zacapu: Vista Hermosa, 2250 m, A. Martínez 372 (ENCB, IEB). Municipio de Zinapécuaro: aproximadamente $1 \mathrm{~km}$ al NW de Jeráhuaro, $2467 \mathrm{~m}$, I. García 8368 (CIMI); desviación a Ucareo, 2350 m, I. García y Y. Hernández 3545 (CIMI); El Cerrito, 2400 m, M. J. Jasso 193 (EBUM, IEB); presa San Andrés al NW de Jeráhuaro, 2470 m, M. J. Jasso 1500 (MEXU). Municipio de Zitácuaro: Coatepec Morelos, 1800 m, I. García 2683 (CIMI, UC); entre El Llano y Calderas al SO de Zitácuaro, F. Chiang 620 (MEXU); Silva de abajo, Cerro Cacique, 2170 m, G. Ibarra 984 (MEXU). Sin registro de municipio: $10 \mathrm{~km}$ al SW de Jacona, carretera a los Reyes, $1770 \mathrm{~m}, J$. C. Soto y L. Cortés 2425 (ENCB); cerca de Pontezuela, 2200 m, J. Rzedowski 42429 (ENCB, IEB); La Palma, 2300 m, F. Ramos s.n. (MEXU).

3. Eryngium bonplandii Delar. f., Eryng. 52. 1808.

E. bonplandianum H.B.K. 1821.

E. microcephalum Willd. \& Spreng. 1841.

E. planum Sessé \& Moc. 1894. No E. planum L. 1753.

E. schaffneri Hemsl. 1897.

E. leptopodum Hemsl. 1897. 
Hierba perenne, glabra, aromática, algo carnosa, caulescente o subacaule; raíces fasciculadas; tallo delgado, erecto, simple o poco ramificado, de 10 a $50 \mathrm{~cm}$ de alto; hojas basales con pecíolos delgados, envainantes en la base, de 2 a $6 \mathrm{~cm}$ de largo, por lo general tan largos o más cortos que las láminas, éstas ovadas u oblongas a lanceoladas, de 2 a $10 \mathrm{~cm}$ de largo y de 1 a $6 \mathrm{~cm}$ de ancho, ápice obtuso o agudo, margen crenado a crenado-aserrado, calloso, venación reticulada; hojas caulinares escasas, alternas o a veces opuestas, semejantes a las basales pero mucho más angostas y en ocasiones dentadas o lobadas; inflorescencias simples o trifurcadas; cabezuelas pocas, pequeñas, pedunculadas, subglobosas, ovoides o elipsoides, de 5 a $15 \mathrm{~mm}$ de largo y de 5 a $10 \mathrm{~mm}$ de diámetro, flores numerosas; brácteas del involucro 6 a 10, angostamente lanceoladas, de 3 a $9 \mathrm{~mm}$ de largo y de 1 a $2 \mathrm{~mm}$ de ancho, agudas, enteras o inconspicuamente espinuloso-aserradas, verdes en ambas caras, más cortas que las cabezuelas; bractéolas semejantes a las brácteas, de 3 a $5 \mathrm{~mm}$ de largo, más largas que el fruto; coma ausente; sépalos ovados, de 1.5 a 2 mm de largo, mucronados; pétalos espatulados, de $1.5 \mathrm{~mm}$ de largo; estilos delgados, más largos que los sépalos; fruto e de 2 a $4 \mathrm{~mm}$ de largo y de 1 a $2 \mathrm{~mm}$ de ancho, con escasas escamas subiguales en la base del cáliz y sobre las costillas.

Habitat, fenología y distribución geográfica. Eryngium bonplandii crece en el sotobosque y claros del bosque de pino-encino y de coníferas, entre los 2000-3400 $\mathrm{m}$ de altitud. Florece de octubre a noviembre y fructifica de diciembre a enero. Se conoce su distribución en el Estado de México, Michoacán, Morelos y San Luis Potosí. En Michoacán se registra de localidades de la Sierra del Centro y de la Sierra Madre del Sur.

Discusión. No se reportan nombres comunes para esta especie. Eryngium bonplandii es morfológicamente parecida a $E$. ghiesbreghtii y a E. gracile, sin embargo $E$. bonplandii presenta hojas con pecíolos delgados, envainantes en la base.

Ejemplares observados: Municipio de Angangueo: Llano del Toro, Sierra de Chincua, 3150 m, M. Mejía s.n. (IEB); Llano Las Papas, J. Rzedowski 52770 (IEB). Municipio de Coalcomán: Baroloso, 2300 m, G. B. Hinton 15380 (ENCB, UC). Municipio de Cotija: Tierras Blancas, 2020 m, I. García 3063, 3777 (CIMI). Municipio de Indaparapeo: $10 \mathrm{~km}$ al S de Indaparapeo, $2250 \mathrm{~m}$, J. Rzedowski 43206 (ENCB, IEB); $11 \mathrm{~km}$ al N de Indaparapeo, 2200 m, J. Rzedowski 45682 (ENCB, IEB, MEXU). Municipio de Nahuatzen: aproximadamente $4 \mathrm{~km}$ carretera San Isidro - entronque Zinziro - Erongarícuaro, 2500 m, I. García 3853 (CIMI); Turícuaro - Cumachuen, 
2380 m, I. García 3355 (CIMI). Municipio de Salvador Escalante: Cerro Timbicho, 2800 m, E. Pérez 901 (IEB); la Lagunita San Gregorio, J. Rzedowski 52802 (IEB). Municipio de Tlalpujahua: alrededores de la Presa Brockman, 2950 m, J. Rzedowski 46018 (IEB). Municipio de Zinapécuaro: aproximadamente $6 \mathrm{~km}$ al SW de Ucareo, 2300 m, I. García 3010 (CIMI, IEB, UC);

\section{Eryngium carlinae Delar., Eryng. 53 t. 23. 1808.}

E. radiatum Willd. 1825.

E. coquimbanum Phil. ex Urban 1879.

E. affine H. Wolff 1909.

Hierba perenne, glabra, acaule o cortamente caulescente; raíz delgada y axonomorfa; tallos generalmente ramificados desde la base, de 5 a $50 \mathrm{~cm}$ de largo, varios, postrados o ascendentes; hojas basales arrosetadas, oblanceoladas u oblongas, subcoriáceas, de 2 a $10 \mathrm{~cm}$ de largo y de 0.5 a $2 \mathrm{~cm}$ de ancho, la base largamente cuneada, ápice obtuso, los márgenes callosos, gruesamente espinuloso-serrados, frecuentemente incisos o lobados, nervaduras pinnado-reticuladas; pecíolos de 0.5 a $2 \mathrm{~cm}$ de largo, anchamente alados, mucho más cortos que la lámina; hojas caulinares escasas, generalmente opuestas, las superiores sésiles, incisas; inflorescencias trifurcadas o escasamente cimoso-divaricadas; cabezuelas pequeñas, generalmente numerosas, de color azul-violeta, de 5 a $12 \mathrm{~mm}$ de largo y de 5 a $10 \mathrm{~mm}$ de ancho, anchamente ovoides a ovoide-cilíndricas, pedunculadas, flores numerosas; brácteas del involucro 8 a 10, cartáceas, extendidas a ascendentes, de 8 a $20 \mathrm{~mm}$ de largo y de 3 a $8 \mathrm{~mm}$ de ancho, linear-lanceoladas a ovadas u oblanceoladas, el haz argénteo, el envés verde o azul, generalmente espinoso-dentadas, sobrepasando las cabezuelas; bractéolas del involucelo de 1.5 a $3 \mathrm{~mm}$ de largo, subuladas, enteras, ligeramente sobrepasando los frutos; coma de 1 a 3 bractéolas casi enteras, de hasta $10 \mathrm{~mm}$ de largo, ocasionalmente ausente; sépalos ovados, de 1.5 a $2 \mathrm{~mm}$ de largo, obtusos, mucronados; pétalos espatulados, de color azul intenso, de $1 \mathrm{~mm}$ de largo; estilos más cortos que los sépalos; frutos ovoides de 1.5 a $2 \mathrm{~mm}$ de largo y de $1 \mathrm{~mm}$ de ancho, densamente cubiertos con papilas vesiculares, las papilas dorsales generalmente todas iguales, las de los ángulos más largas, planas y cónicas.

Habitat, fenología y distribución geográfica. Eryngium carlinae crece en praderas, pastizales, habitats perturbados del bosque de encino, pino-encino y de coníferas, entre los 1900-3500 m de altitud. Florece de mayo a julio y fructifica de agosto a enero. Se conoce su distribución en el Distrito Federal, Durango, Estado 
de México, Michoacán, Hidalgo hasta el sur de México; Guatemala, Costa Rica y Sudamérica. En Michoacán se registra a lo largo y de ambos lados de la Sierra del Centro y región de los Valles y Ciénagas.

Discusión. Eryngium carlinae conjuntamente con E. beecheyanum son ampliamente conocidas como hierba o yerba del sapo y mosquitas y son empleadas en la medicina vernácula. E. carlinae es muy variable, morfológicamente es parecida a $E$. beecheyanum, sobre todo en etapas tempranas de su desarrollo o en ejemplares de porte alto, sin embargo difieren en que E. carlinae es perenne, de tallo más corto y más ramificado cerca de la base, casi siempre de hábito postrado y presenta generalmente las papilas vesiculares dorsales del fruto usualmente iguales, escamas aplanadas en los ángulos y los estilos más cortos que los sépalos.

Ejemplares observados: Municipio de Angangueo: Las Papas, $3100 \mathrm{~m}, I$. García y M. García 2371 (CIMI); Las Papas, Sierra de Chincua, 3100 m, I. García 2000 (CIMI); Llano de Las Papas, 3150 m, J. C. Soto 1525 (MEXU); Reserva de la Mariposa Monarca, 3100 m, I. García y Y. Hernández 3559 (CIMI). Municipio de Churintzio: Los Ocales - Sanguijuelas, 1850 m, J. N. Labat 1631 (MEXU). Municipio de Epitacio Huerta: $0.5 \mathrm{~km}$ al NW de Epitacio Huerta, $2450 \mathrm{~m}$, I. García y A. García 3232 (CIMI, UC). Municipio de Erongarícuaro: Cerro del Bosque $3 \mathrm{~km}$ al NW de Puácuaro, 2200 m, E. Mayo 407 (IEB). Municipio de Hidalgo: Laguna Larga - Los Azufres; 2800 m, C. L. Díaz-Luna 9706 (UC); route 15 ca. $23.5 \mathrm{~km}$ of Ciudad Hidalgo, ca. 2300 m, W. R. Cruden 1341 (INIF, UC); summit of Cerro San Andrés, ca. $12 \mathrm{~km}$ airline $\mathrm{N}$ of Ciudad Hidalgo, $3589 \mathrm{~m}$, J. H. Beaman 4265 (UC); SW side Cerro San Andrés, ca. 3100 m, J. H. Beaman 4354 (UC): 5 mi of Mil Cumbres, J. D. Sauer 1106 (UC) Municipio de Morelia: $15 \mathrm{~km}$ al SW de Morelia, carretera a Guadalajara, $2050 \mathrm{~m}$, J. C. Soto 2379 (ENCB); fraccionamiento Colinas del Sur, 1980 m, B. E. López 30 (EBUM); Loma de los Encinos, Santa María Guido, 2060 m, B. E. López 16 (EBUM); NE de la Presa Cointzio, S. Zamudio y R. Murillo 4531 (IEB). Municipio de Nuevo Parangaricutiro: aprox. $2 \mathrm{~km}$ al W de El Tepetate, I. García y J. A. Machuca 4162 (CIMI); lado E, base del Cerro Piedra del Horno, I. García et al. 4774, 6150 (CIMI). Municipio de Pátzcuaro: $2.5 \mathrm{~km}$ al SE de Ajuno, carretera Pátzcuaro - Uruapan, $2160 \mathrm{~m}, J$. Espinosa 2189 (IEB); Cerro Los Lobos $5 \mathrm{~km}$ al SE de Tzurumútaro, $2150 \mathrm{~m}, J$. Espinosa 1810 (IEB). Municipio de Quiroga: route 15, ca. $12 \mathrm{mi}$ E of Quiroga, ca. $7000 \mathrm{ft}$., J. L. Strother y G. E. Pilz 1084 (MEXU, UC). Municipio de Senguio: $0.5 \mathrm{~km}$ al N de la Presa Chincua, $2420 \mathrm{~m}, I$. García 3656 (CIMI). Municipio de Tlalpujahua: $2 \mathrm{~km}$ al W de Tlacotepec, 2550 
m, I. García y Y. Hernández 3537 (CIMI); aproximadamente 0.5 km, al SE de San Francisco de los Reyes, 2500 m, I. García y Y. Hernández 3584 (IEB); carretera Santa María - San José de Guadalupe, 2500 m, I. García y Y. Hernández 3556 (CIMI); presa Brockman, 2760 m, I. García y Y. Hernández 3609 (CIMI); San Francisco de los Reyes, 2600 m, I. García 3228 (CIMI); San Francisco de los Reyes, 2500 m, I. García y Y. Hernández 3524, 3526 (CIMI). Municipio de Tzintzuntzan: alrededores de Sanabria, 2060 m, J. Espinosa 2166 (IEB). Municipio de Uruapan: Barranca del Cupatitzio, 1810 m, X. Madrigal 2963 (EBUM, INIF); Uruapan - Apatzingán road 2.3 mi S Uruapan, $5300 \mathrm{ft}, C$. R. Bell y J. A. Duke 16689 (UC). Municipio de Villa Madero: $6 \mathrm{~km}$ al SE de Villa Madero, carretera a Nocupétaro, $2400 \mathrm{~m}, J$. $C$. Soto 4735 (ENCB). Municipio de Zinapécuaro: $1 \mathrm{~km}$ al N de Jeráhuaro, $2450 \mathrm{~m}, M$. J. Jasso 1586 (CIMI, IEB); lado SE de la presa Gachupina, 2920 m, M. J. Jasso 769 (CIMI, IEB); S de Laguna Larga, Los Azufres, 2780 m, E. Carranza 278 (EBUM).

\section{Eryngium cervantesii Delar., Eryng. 47. t. 18, f. 1. 1808.}

Hierba perenne, glabra, baja; raíz pivotante; tallo caulescente, ramificado desde la base, de 6 a $15 \mathrm{~cm}$ de largo, rastrero a procumbente, extendiéndose radialmente; hojas basales con pecíolos hasta de $2 \mathrm{~cm}$ de largo, con la base envainante, láminas lineares a estrechamente espatuladas, de 2 a $4 \mathrm{~cm}$ de largo y de 1 a $4 \mathrm{~mm}$ de ancho, margen ligeramente aserrado a manifiestamente lobado, nervación pinnadamente reticulada; hojas caulinas sésiles o subsésiles, opuestas o en fascículos, con el margen tres o más veces lobado; cabezuelas pequeñas, sobre pedúnculos cortos, dispuestas en las axilas de las hojas, globosas, de 3 a $6 \mathrm{~mm}$ de diámetro, flores numerosas de color rosa; brácteas del involucro 5 o 6 , rígidas, extendidas a ascendentes, lanceoladas, de 3 a $12 \mathrm{~mm}$ de largo, enteras, espinosas en el ápice, la base ensanchada, escariosa; bractéolas parecidas a las brácteas, de 3 a $4 \mathrm{~mm}$ de largo, ligeramente excediendo las flores y al fruto; coma ausente; sépalos ovados, de cerca de $1 \mathrm{~mm}$ de largo, obtusos, apiculados; pétalos ovales, de cerca de $0.5 \mathrm{~mm}$ de largo; estilos delgados, excediendo el largo de los sépalos; fruto ovoide, de 2 a $3 \mathrm{~mm}$ de largo y de $1.5 \mathrm{~mm}$ de ancho, cubierto de escamas blancas de dos tipos, unas cuantas en la parte superior, laminares, ovadas, de alrededor de $1 \mathrm{~mm}$ de largo y en el resto de la superficie filamentosas, linear-atenuadas, aproximadamente del mismo largo.

Habitat, fenología y distribución geográfica. Eryngium cervantesii vive en lugares planos con pastizales húmedos, cercanos al bosque tropical caducifolio y al bosque de encino, en ambientes semiacuáticos o terrenos de suelo húmedo; prospera 
entre los 2000-2800 m de altitud. Florece de mayo a julio y fructifica de agosto a octubre. Se conoce su distribución en el Estado de México, Hidalgo y Michoacán. En Michoacán se registra de la región de los Valles y Ciénagas.

Discusión. No se reportan nombres locales para esta especie. Eryngium cervantesii se asemeja morfológicamente a $E$. pilularioides, la que se desarrolla en ambientes y hábitos muy similares, sólo que esta última presenta las hojas cilíndricas, fistulosas, a veces aplanadas, venación paralela, a menudo septadas; hasta ahora se conoce únicamente del estado de Hidalgo.

Ejemplares observados: Municipio de Epitacio Huerta: $0.5 \mathrm{~km}$ al NW de Epitacio Huerta, 2450 m, I. García y A. García 3233 (CIMI, UC); 4 km al NW de Epitacio Huerta, 2450 m, I. García y A. García 3236 (CIMI); lado NW de la cortina Presa Tepuxtepec, I. García 5761 (CIMI). Municipio de Tlalpujahua: cultivado en San Francisco de los Reyes, 2520 m, I. García 3652 (CIMI); La Cima, presa Brockman, 2800 m, I. García y Y. Hernández 3534 (CIMI). Municipio de Villa Jiménez: alrededores de Copándaro, 2000 m, J. Rzedowski 48890 (IEB); Presa Aristeo Mercado, 2000 m, E. Pérez 1249 (EBUM, IEB).

\section{Eryngium columnare Hemsl., in Hook. Ic. 26: t. 2511. 1897.}

Hierba perenne, glabra, erecta; raíces carnosas, fasciculadas, saliendo de un tallo corto, grueso y leñoso; tallo solitario de $40 \mathrm{~cm}$ a $1.2(1.5) \mathrm{m}$ de alto; hojas basales dispuestas en roseta, linear-lanceoladas, de 20 a $50 \mathrm{~cm}$ de largo y de 8 a $15 \mathrm{~mm}$ de ancho, base ensanchada, ápice acuminado, margen finamente espinoso-lobado, con los dientes extendidos o ascendentes, de 0.3 a $1.7 \mathrm{~cm}$ de largo, con frecuencia cada uno acompañado de una (o más) espinas más cortas, ápice acuminado, venación paralela; hojas caulinares semejantes a las basales, sésiles, las inferiores alternas, las superiores a veces opuestas con los dientes y el ápice bastante alargado; inflorescencia por lo común cimoso-ramificada o cabezuelas solitarias o hasta 5, largamente pedunculadas, de color azul oscuro, ovoides u oblongas, de 1 a $4 \mathrm{~cm}$ de largo y de 1 a $2.5 \mathrm{~cm}$ de ancho, con numerosas flores; brácteas del involucro 9 a 13, rígidas, con frecuencia retrorsas, linear-lanceoladas, de 2 a $5.5 \mathrm{~cm}$ de largo y de 3 a $8 \mathrm{~mm}$ de ancho, enteras o algo espinoso-dentadas hacia la base, usualmente más largas que las cabezuelas; bractéolas lanceoladas, de 5 a $6 \mathrm{~mm}$ de largo, puntiagudas, enteras, sobrepasando el largo del fruto; coma ausente; sépalos ovado-oblongos, de alrededor de $2 \mathrm{~mm}$ de largo, acuminados, mucronados; pétalos oblongos, de $2 \mathrm{~mm}$ de largo; 
estilos delgados, de $2.5 \mathrm{~mm}$ de largo, excediendo los sépalos; fruto turbinado, de 3 a $4 \mathrm{~mm}$ de largo y de $2 \mathrm{~mm}$ de ancho, escamas laterales formando dos alas enteras, o casi enteras acuminadas distalmente, el resto del fruto desnudo.

Habitat, fenología y distribución geográfica. Eryngium columnare crece en el sotobosque y claros del bosque de encino y de coníferas, entre los 2500-2800 m de altitud. Florece de junio a agosto y fructifica de septiembre a enero. Se distribuye en el Estado de México, Hidalgo, Michoacán, Morelos y Tamaulipas. En Michoacán se conoce de tres localidades de la Sierra del Centro.

Discusión. No se reportan nombres locales para esta especie. Aparentemente Eryngium columnare se asemeja morfológicamente y en hábito a $E$. mexiae y $E$. cymosum; sin embargo, E. columnare se distingue por sus cabezuelas ovoide-cilíndricas de color azul o púrpura con brácteas del involucro replegadas.

Ejemplares observados: Municipio de Epitacio Huerta: San Cristóbal, E. Pérez y S. Zamudio 3441 (IEB). Municipio de Tangancícuaro: noroccidente del Cerro Patamban, J. Rzedowski y R. McVaugh 661 (ENCB, IEB). Municipio de Tlalpujahua: cerro de las antenas de microondas (Cerro Somera), límite Michoacán - Estado de México, 2850 m, I. García et al. 3528, 3529 (CIMI); cultivado en San Francisco de los Reyes, 2520 m, I. García 3651 (CIMI).

\section{Eryngium comosum Delar., Eryng. 30. t. 7. 1808.}

Hierba perenne, glabra, erecta; raíces gruesas, tuberosas; tallos ramificados, de 15 a $40 \mathrm{~cm}$ de alto; hojas basales sobre pecíolos alados, con frecuencia espinosos, de 2 a $8 \mathrm{~cm}$ de largo, más cortos que las láminas, éstas oblongas a obovadas, de 8 a $15 \mathrm{~cm}$ de largo y de 3 a $5 \mathrm{~cm}$ de ancho, profundamente pinnatífidas a bipinnatisectas con divisiones lanceoladas, rígidas, espinosas, venación pinnadamente reticulada; hojas caulinas semejantes a las basales, las superiores opuestas, sésiles, profundamente partidas; inflorescencia varias veces trifurcada o cimosa; cabezuelas pedunculadas, cilíndricas, de 1 a $3 \mathrm{~cm}$ de largo y de 6 a $8 \mathrm{~mm}$ de diámetro, con numerosas flores; brácteas del involucro 5 a 6(8), rígidas, extendidas o retrorsas, lanceoladas u oblanceoladas, de 1 a $1.5 \mathrm{~cm}$ de largo, trifurcadas o a veces apicalmente pinnatífidas, amarillentas en su cara adaxial; bractéolas subuladas, de 3 a $4 \mathrm{~mm}$ de largo, curvadas, ensanchadas hacia la base, más o menos de igual largo que el fruto; coma de 2 a 4 bractéolas subiguales, enteras o trifurcadas, de 8 a $15 \mathrm{~mm}$ de largo; 
sépalos ovado-lanceolados, de 1.5 a $2 \mathrm{~mm}$ de largo, agudos y mucronados; pétalos espatulados, de 1 a $2 \mathrm{~mm}$ de largo; estilos delgados de 1.8 a $2.2 \mathrm{~mm}$ de largo; fruto globoso-ovoide, de 2 a $4 \mathrm{~mm}$ de largo y de 1 a $2 \mathrm{~mm}$ de ancho, densamente cubierto por escamas blancas o amarillentas, lanceolado-acuminadas, las de los ángulos un poco más largas que el resto.

Habitat, fenología y distribución geográfica. Eryngium comosum crece en planicies y pastizales derivados de matorral espinoso y claros del bosque de encino, en ambientes secos, entre los 1900-2300 m de altitud. Florece de junio a agosto y fructifica de septiembre a noviembre. Se conoce su distribución en el Distrito Federal, Guerrero, Hidalgo, Michoacán y Querétaro. En Michoacán se conoce de localidades al norte de la Sierra del Centro y Región de los Valles y Ciénagas.

Discusión. En el Valle de México se reporta como hierba del sapo y piñitas; localmente no se le conoce algún epíteto común. Morfológicamente esta especie podría relacionarse por su apariencia con E. beecheyanum y E. heterophyllum, sin embargo el bajo porte, la frondosidad o la amplia ramificación y la presencia de espinas de E. comosum son destacables.

Ejemplares observados: Municipio de Contepec: $0.5 \mathrm{~km}$ al $\mathrm{N}$ de Venta de Bravo, 2250 m, I. García y A. García 3235 (CIMI, UC); aproximadamente 2 km al NW de Venta de Bravo, 2250 m, I. García y Y. Hernández 3528 (CIMI); aproximadamente $500 \mathrm{~m}$ al sur de la caseta Venta de Bravo (de la autopista Morelia - Atlacomulco), salida hacia Tlalpujahua, I. García et al. 8292 (CIMI). Municipio de Zinapécuaro: Huingo, ca. Estación FFCC, 1900 m, J. M. Escobedo 1990 (IEB).

8. Eryngium cymosum Delar., Eryng. 63. t. 31. 1808.

Hierba perenne, glabra, robusta, caulescente; raíces fasciculadas, fibrosas y blandas; tallos solitarios, erectos, de 60 a $80 \mathrm{~cm}$ de alto; hojas basales numerosas, linear-lanceoladas, de 20 a $60 \mathrm{~cm}$ de largo y de 6 a $18 \mathrm{~mm}$ de ancho, láminas con la base dilatada, ápice agudo, espinoso-serradas con dientes extendidos, los más largos de 1 a $3 \mathrm{~cm}$, espinas axilares presentes, la venación paralela, vainas tan anchas como las láminas, de 2 a $5 \mathrm{~cm}$ de largo; hojas del tallo similares a las basales, pocas, sésiles, muy espinosas especialmente en la base, las inferiores alternas, ascendentes, las superiores reducidas, opuestas, extendidas o recurvadas; inflorescencia en forma de cima ramificada con numerosas cabezuelas, pedunculadas, cabezuelas globosas 
a hemisféricas, de 1.5 a $2 \mathrm{~cm}$ de largo y de 10 a $15 \mathrm{~mm}$ de diámetro, con numerosas flores; brácteas 6 a 8, rígidas, extendidas a un poco retrorsas, linear a linear-lanceoladas, de 8 a $24 \mathrm{~mm}$ de largo y de 2 a $3 \mathrm{~mm}$ de ancho, pungentes, enteras o con $1 \mathrm{o}$ 2 espinas marginales obsoletas, usualmente excediendo por mucho las cabezuelas; bractéolas linear-lanceoladas, de 3 a $5 \mathrm{~mm}$ de largo, pungentes, enteras, excediendo el fruto; coma ausente; sépalos ovados, de cerca de $1.5 \mathrm{~mm}$ de largo, agudos, mucronados; pétalos ovales, de 1 a $1.5 \mathrm{~mm}$ de largo; estilos delgados de $1.8 \mathrm{~mm}$ de largo; fruto ovoide, de 2 a $2.5 \mathrm{~mm}$ de largo y de 1 a $2 \mathrm{~mm}$ de ancho, las escamas calicinas 5 a 7, laterales, planas, lanceoladas, de hasta $1 \mathrm{~mm}$ de largo, la porción media e inferior desnuda.

Habitat, fenología y distribución geográfica. Eryngium cymosum crece en laderas y sotobosque de bosques de coníferas, entre los 2000-3200 m de altitud. Florece de julio a octubre y fructifica de octubre a enero, en ambientes sombreados. Se conoce su distribución en el Estado de México, Guerrero, Hidalgo y Michoacán. En Michoacán se conoce de localidades de la Sierra del Centro.

Discusión. No se reportan nombres locales para esta especie. Morfológicamente $E$. cymosum es algo parecida a $E$. mexiae, sin embargo esta última presenta las hojas del tallo dísticas, las cabezuelas ovoides a globosas y la superficie dorsal del fruto es desnuda; las brácteas de E. cymosum se presentan extendidas y son de mayor longitud.

Ejemplares observados: Municipio de Hidalgo: $10 \mathrm{mi}$ al N y NW de Ciudad Hidalgo, $3000 \mathrm{~m}$, R. McVaugh 9876 (MEXU). Municipio de Tlalpujahua: Rosa Azul, Sierra de Chincua, 2800 m, I. García 3094 (CIMI, UC), I. García 3546 (CIMI); Municipio de Zacapu: Cerro La Arena, $2460 \mathrm{~m}, \mathrm{~F}$. Takaki sitio 148-I-10 (INIF); El Mogote Grande, $2600 \mathrm{~m}$, A. Mancera S-144 (INIF). Municipio de Zinapécuaro: $4 \mathrm{~km}$ al E de Taimeo, sobre el camino a Maravatío, $2100 \mathrm{~m}$, J. Rzedowski 46055 (CIMI, IEB, UC); al S de Laguna Larga, Los Azufres, 2750 m, I. García 3096 (CIMI, UC); Cerro El Chino, Los Azufres, 2950 m, S. Zamudio 6007 (IEB); lado NE de la presa Pízcuaro, 3050 m, M. J. Jasso 1000 (CIMI, IEB).

9. Eryngium ghiesbreghtii Decaisne, Bull. Soc. Bot. Fr. 20: 21. 1873.

Hierba perenne, glabra, erecta; raíces fasciculadas, leñoso-fibrosas; tallos generalmente solitarios, de 30 a $150 \mathrm{~cm}$ de alto, ampliamente ramificados arriba; hojas 
basales dísticas, agregadas, triangulares a ovado-cordadas, subcoriáceas, de 3 a 10 $\mathrm{cm}$ de largo y de 2 a $7 \mathrm{~cm}$ de ancho, la base generalmente caudada, finamente espinuloso-serradas, el ápice agudo, nervaduras pinnado-reticuladas; pecíolos de 5 a 20 cm de largo, angosta y largamente envainadores, más largos que las láminas; hojas caulinares inferiores similares a las basales, las superiores sésiles, amplexicaules, opuestas; inflorescencia trifurcada; cabezuelas pequeñas, numerosas, globosas, de 3 a $7 \mathrm{~mm}$ de diámetro, pedunculadas, flores numerosas; brácteas del involucro 6 a 8 , cartáceas, de 5 a $15 \mathrm{~mm}$ de largo y de 1.5 a $4 \mathrm{~mm}$ de ancho, oblongo-lanceoladas a ovadas, retrorsas, sobrepasando mucho las cabezuelas, el haz blanquecino o argénteo, el envés verde, los márgenes callosos, enteros; bractéolas del involucelo de 3 a $5 \mathrm{~mm}$ de largo, linear-subuladas, sobrepasando a los frutos; coma ausente; sépalos ovado-lanceolados, de 1 a $1.5 \mathrm{~mm}$ de largo, agudos, mucronados; pétalos oblanceolados, de $1 \mathrm{~mm}$ de largo, blanco-verdosos a azuloso-pálidos; estilos delgados, excediendo con mucho los sépalos; frutos de 1 a $2 \mathrm{~mm}$ de largo y de 1 a $1.5 \mathrm{~mm}$ de ancho, ovoide-globosos, comprimidos lateralmente, densamente cubiertos con vesículas de color ámbar oscuro o blanquecino, las superiores y laterales lanceoladas u ovadas, agudas, aplanadas, las inferiores papilosas.

Habitat, fenología y distribución geográfica. Eryngium ghiesbreghtii crece en laderas húmedas y barrancas en el bosque tropical caducifolio y bosques de pinoencino, entre los 900-2500 m de altitud. Florece de julio a agosto y fructifica de septiembre a noviembre. Su distribución geográfica abarca Chiapas, Estado de México, Guerrero, Michoacán, Morelos, Oaxaca; así como Guatemala. En Michoacán se conoce de localidades de la Sierra del Centro, en la ladera sur de este sistema cerca de la Región de Tierra Caliente y de la Sierra Madre del Sur.

Discusión. No se reportan nombres locales para esta especie. E. ghiesbreghtii presenta cierto parecido en su morfología con E. gracile, principalmente por sus hojas envainantes, sin embargo se diferencia en que $E$. ghiesbreghtii las tiene agudas espinuloso-serradas y no calloso-marginadas, las basales son cordadas en la base y su fruto está cubierto densamente con vesículas.

Ejemplares observados: Municipio de Ario de Rosales: km 26.5 carretera Ario de Rosales - La Huacana, 1180 m, I. García y S. Zamudio 3364 (CIMI). Municipio de Cotija: Agua de Maguey aproximadamente $25 \mathrm{~km}$ al S de Jiquilpan, 2300 m, I. García y J. Nava 2983 (CIMI, IEB, UC); camino a Los Pilares, al S de Gallineros, I. García y J. Nava 3780 (CIMI). Municipio de Tacámbaro: 6 km north of Paso 
de Morelos, 1550 m, V. W. Steinmann 4718 (CIMI, IEB). Municipio de Tancítaro: 3 $\mathrm{km}$ al E de Apo, camino a Parastaco, I. García 5068 (CIMI); camino Tancítaro - El Jazmín por el Cerro La Cantera, I. García et al. 4354 (CIMI); Tancítaro, 2000 m, G. B. Hinton 5612 (UC). Municipio de Uruapan: Cerro de Carboneras above Rio Cupatitzio, ca. $22 \mathrm{~km} \mathrm{~S}$ of Uruapan, 3300-3700 ft, R. M. King y T. R. Soderstrom 4862 (UC); Cerro de los Puercos, 1666 m, I. Viveros y A. Mancera 23 (INIF); Tzararacua (waterfalls) of hwy $37 \mathrm{a}$ few mi, S of Uruapan tourist area, $1530 \mathrm{~m}, \mathrm{~J}$. Swagel 151 (UC). Municipio de Zitácuaro: localidad zona 11, Cerro Chato, G. Ibarra 874 (MEXU).

10. Eryngium gracile Delar. f., Eryng. 54. t. 24. 1808.

E. longirameum Turcz. 1847.

E. paucisquamosum Hemsl. 1897.

Hierba perenne, glabra, delgada, caulescente; raíces fibroso-leñosas; tallos erectos, de 25 a $90 \mathrm{~cm}$ de alto, ramificándose arriba; hojas basales ovadas a oblongas, de 3 a $8 \mathrm{~cm}$ de largo y de 2 a $5.5 \mathrm{~cm}$ de ancho, profundamente cordadas a redondeadas en la base, obtusas en el ápice, calloso-marginadas, crenadas o escasamente crenado-serradas, la venación palmadamente reticulada; pecíolos de vainas estrechas en la base, de 2 a $30 \mathrm{~cm}$ de largo, usualmente excediendo las láminas; hojas caulinares pocas, las inferiores parecidas a las basales, las superiores muy reducidas, sésiles, opuestas; cabezuelas en la parte terminal de los tallos o en las ramas más pequeñas, pedunculadas; cabezuelas solitarias, globosas, de 4 a $7 \mathrm{~mm}$ de diámetro, azulosas, flores numerosas; brácteas del involucro 8 a 12, cartáceas, retrorsas, oblongas a oblongo-ovales, de 4 a $15 \mathrm{~mm}$ de largo y de 2 a $5 \mathrm{~mm}$ de ancho, obtusas o abruptamente agudas, enteras o con unos pocos dientes espinulosos pequeños, de color azul amatista o glaucos en el haz y verdes en el envés, excediendo con mucho las cabezuelas; bractéolas subuladas, de 3 a $4 \mathrm{~mm}$ de largo, dilatadas en la base, enteras, excediendo ligeramente o con mucho el fruto; coma ausente; sépalos lanceolados, de 1 a $1.5 \mathrm{~mm}$ de largo, agudos, mucronulados, enteros; pétalos oblongo-espatulados, de cerca de $1 \mathrm{~mm}$ de largo; estilos delgados, de 1.3 a $1.7 \mathrm{~mm}$ de largo; fruto ovoide, de 1.5 a $2 \mathrm{~mm}$ de largo y de $1.4 \mathrm{~mm}$ de ancho, con unas pocas escamas laterales lanceoladas, hacia la parte superior, las dorsales menores, pocas $\mathrm{o}$ ausentes a lo largo, arregladas en hileras.

Habitat, fenología y distribución geográfica. Eryngium gracile crece en el sotobosque y laderas del bosque de pino-encino y pino, entre los 1450-2500 m de 
altitud. Florece de julio a septiembre y fructifica de septiembre a diciembre. Su distribución geográfica abarca Chiapas, Estado de México, Guerrero, Michoacán hasta Oaxaca; así como Guatemala. En Michoacán se conoce de varias localidades de la Sierra del Centro y de la Sierra Madre del Sur.

Discusión. Esta especie no tiene nombres locales en esta entidad. E. gracile se relaciona morfológicamente con E. ghiesbreghtii, sin embargo la primera presenta las hojas ovadas a oblongas y obtusas, crenado-serradas y las brácteas del involucro son muy evidentes por su tamaño y forma extendida, las bractéolas también son largas, el fruto tiene escamas muy escasas; las hojas basales en E. ghiesbreghtii son ampliamente caudadas en la base, en E. gracile la base es redondeada.

Ejemplares observados: Municipio de Coalcomán: 3-6 km, SE of aserradero Dos Aguas y nearly W of Aguililla, 2000-2100 m, R. McVaugh 24721 (UC); Baroloso, 2300 m, G. B. Hinton 15381 (UC). Municipio de Cotija: Tierras Blancas, cerca de Gallineros, 2020 m, I. García 3064, 3776 (CIMI). Municipio de Morelia: 4 km al S de San Miguel del Monte, 2400 m, J. Rzedowski 44922 (ENCB, IEB, UC); Agua Zarca al SE de San Miguel del Monte, C. Medina 1414 (IEB); Agua Zarca, camino a Pico Azul, E. García y E. Pérez 4035 (IEB); Cerro El Laurelito al S de San José de las Torres, 2000 m, J. Rzedowski 37607 (IEB); Cerro Pico Azul, 2500 m, E. García 3439 (EBUM, IEB); Morelia - Cerro Azul, 2000-2300 m, G. Arsène 2456 (MEXU); parte alta del Cerro Pico Azul, cerca de San José de las Torres, 2550 m, J. Rzedowski 45997 (IEB, MEXU); Cerro Pico Azul, ca. de San José de las Torres, 2300 m, J. Rzedowski 42203 (CHAP, IEB, UC); Puerto La Tijera, C. Medina 2104 (IEB); El Capulín - Ichaqueo, J. N. Labat 2487 (IEB). Municipio de Nahuatzen: Cerro Irepu al SE de Sevina, E. García y E. Pérez 3372 (IEB). Municipio de Salvador Escalante: $2 \mathrm{~km}$ al S de Villa Escalante, J. C. Soto 3422 (MEXU); Opopeo, 2350 m, J. M. Escobedo 653 (IEB). Municipio de Tacámbaro: Las Cascadas, arriba de Tacámbaro, J. Kishler 506 (MEXU). Municipio de Uruapan: Cerro de los Puercos, 1666 m, A. Mancera e I. Viveros S-114-II-4 (INIF); pine forest Uruapan, C. G. Pringle 10143 (IEB).

11. Eryngium heterophyllum Engelm. in Wisliz. Tour N. Mex. 106. 1848.

E. wrigthii A. Gray 1852.

E. medium Hemsl. 1903.

E. altamiranoi Hemsl. \& Rose 1906.

E. confusum Hemsl. \& Rose 1906.

E. endlichii H. Wolff 1910. 
Hierba perenne, glabra, caulescente; raíz engrosada; tallos erectos, de 20 a $60(80) \mathrm{cm}$ de alto; hojas basales rosuladas, estrechamente oblanceoladas a oblongoovales, de 4 a $12 \mathrm{~cm}$ de largo y de 1 a $3 \mathrm{~cm}$ de ancho, cuneadas en la base, agudas u obtusas en el ápice, las rosetas estériles setoso-dentadas, las fértiles espinosoaserradas a pinnatífidas o bipinnatisectas, los dientes o lóbulos agudos, pungentes, calloso-marginados, la venación pinnadamente reticulada; pecíolos estrechamente alados, envainantes en la base, de 1 a $5 \mathrm{~cm}$ de largo, más cortos que las láminas; hojas caulinares numerosas, pareciendo a las basales, las inferiores pinnatífidas o bipinnatisectas, las superiores opuestas, sésiles y palmadamente partidas; inflorescencia ramificada a manera de panícula, las cabezuelas pequeñas, numerosas, pedunculadas, flores numerosas; cabezuelas ovoides, de 7 a $15 \mathrm{~mm}$ de largo y de 5 a $10 \mathrm{~mm}$ de ancho, de color azul a blanco; brácteas del involucro 8 a 14, rígidas, extendido-ascendentes, linear-lanceoladas a lanceoladas, de 12 a $25 \mathrm{~mm}$ de largo y de 2 a $5 \mathrm{~mm}$ de ancho, pungentes a acuminadas, con 1 a 2 pares de dientes espinosos o enteras, verdes o azulosas abajo y blanco-amarillentas arriba, excediendo el largo u ocasionalmente más cortas que las cabezuelas; bractéolas subuladas, de 3 a $5 \mathrm{~mm}$ de largo, enteras, curvadas, excediendo el largo del fruto; coma de 1 a 4 brácteas enteras, de 5 a $15 \mathrm{~mm}$ de largo u ocasionalmente obsoleta; sépalos ovados, de cerca de $1 \mathrm{~mm}$ de largo, obtusos a truncados, apiculados; pétalos oblanceolados a obovados, de cerca de $1 \mathrm{~mm}$ de largo; estilos delgados, excediendo los sépalos; fruto ovoide, de 1.5 a $2.5 \mathrm{~mm}$ de largo y $1.2 \mathrm{~mm}$ de ancho, con escamas planas debajo de los sépalos y ángulos superiores.

Habitat, fenología y distribución geográfica. Eryngium heterophyllum crece en el pastizal y vegetación secundaria derivada del ecotono entre el bosque tropical caducifolio y el bosque de encino, a los $2000 \mathrm{~m}$ de altitud en ambientes secos. Florece de julio a agosto y fructifica de septiembre a octubre. Su distribución geográfica se extiende en Louisiana, Texas y sur de Arizona en Estados Unidos de América; de México se registra de Chihuahua, Durango, Estado de México, Jalisco, Michoacán, Oaxaca y San Luis Potosí. En Michoacán se conoce de un par de localidades al norte de la Sierra del Centro en el noreste y noroeste de la entidad.

Discusión. Eryngium heterophyllum es nombrado localmente hierba del sapo de manera similar a E. beecheyanum, E. carlinae, E. comosum y E. spiculosum. De igual forma se relaciona morfológicamente con las primeras tres especies, sobre todo con E. beecheyanum, ya que algunos ejemplares de porte alto pueden confundirse con E. heterophyllum, sin embargo esta última es perenne, su raíz es gruesa y 
leñosa, las hojas basales son más largas y más anchas, los pecíolos más largos, fruto con escamas planas bajo los sépalos, las papilas del fruto son elongadas y setiformes; E. carlinae presenta hojas basales postradas enteras, en E. comosum las hojas y brácteas llevan mayor presencia de espinas.

Ejemplares observados: Municipio de Churintzio: Las Buelleras - Sanguijuelas, J. N. Labat 1631, 1723 (IEB, MEXU). Municipio de Maravatío: aproximadamente $2 \mathrm{~km}$ al N de Maravatío, cerca de autopista, $1960 \mathrm{~m}$, I. García et al. 3655 (CIMI).

12. Eryngium longifolium Cav., Anal. Hist. Nat. 2: 133. 1800.

E. watsonii Coult. \& Rose 1905.

E. langlassei $\mathrm{H}$. Wolff 1911.

Hierba perenne, glabra, caulescente, delgada; raíz principal tuberosa, con raíces secundarias fibrosas; tallo solitario, de 0.5 a $2 \mathrm{~m}$ de alto, erecto, ramificado; hojas basales numerosas, lineares, de 30 a $70 \mathrm{~cm}$ de largo y de 1 a $2 \mathrm{~cm}$ de ancho, más anchas en la base, atenuadas hacia el ápice, débilmente espinoso-ciliadas, las espinas escasas, ascendentes, las mayores de 2 a $6 \mathrm{~mm}$ de largo, espinas axilares menudas o ausentes, la venación paralela; vainas de las hojas más anchas que las láminas, vaginadas, de 6 a $12 \mathrm{~cm}$ de largo; hojas caulinares pocas, similares a las basales, amplexicaules, alternas, ascendentes, las superiores muy reducidas, opuestas; inflorescencia divaricadamente cimosa, las cabezuelas numerosas, pedunculadas; cabezuela globosa-ovoide a ovoide-cilíndrica, de 8 a $15 \mathrm{~mm}$ de largo y de 8 a $10 \mathrm{~mm}$ de ancho, redondeada en el ápice y base, flores numerosas; brácteas del involucro 6 a 8, rígidas, extendidas a algo reflejas, linear-lanceoladas, de 3 a $12 \mathrm{~mm}$ de largo y de $1 \mathrm{~mm}$ de ancho, pungentes, enteras, mucho más cortas que las cabezuelas; bractéolas estrechamente lanceoladas, de 3 a $5 \mathrm{~mm}$ de largo, pungentes, enteras, ocasionalmente puberulentas, ligeramente excediendo el fruto; coma ausente; sépalos anchamente ovados, de $1 \mathrm{~mm}$ de largo, obtusos, apiculados; pétalos ovales, de cerca de $1 \mathrm{~mm}$ de largo; estilos delgados, de 1.1 a $1.2 \mathrm{~mm}$ de largo; fruto turbinado, de 2 a $3 \mathrm{~mm}$ de largo y de $1.8 \mathrm{~mm}$ de ancho, escamas 5 o 6 , las laterales lanceoladas, de 0.6 a $1 \mathrm{~mm}$ de largo, las dorsales reducidas u obsoletas.

Habitat, fenología y distribución geográfica. Eryngium longifolium crece en planicies y laderas de bosques de encino, encino-pino, entre los 1500-3000 m de altitud. Florece de julio a agosto y fructifica de septiembre a diciembre. Se distri- 
buye en el Estado de México, Guerrero, Hidalgo, Jalisco, Michoacán y Oaxaca. En Michoacán se conoce de varias localidades de la Sierra del Centro y de la Sierra Madre del Sur.

Discusión. No se conocen reportes de nombres locales para esta especie. Eryngium longifolium se relaciona morfológicamente con E. sparganophyllum; sin embargo el primero presenta los márgenes de las hojas con espinas cortas, menor número de brácteas y la cabezuela es verdosa.

Ejemplares observados: Municipio de Aguililla: 8-10 km al SE del aserradero Dos Aguas, R. McVaugh 24765 (UC). Municipio de Charo: ca. $18 \mathrm{mi}$ al E de Morelia, R. M. King y T. R. Soderstrom 5013 (UC). Municipio de Cherán: 10.8 mi al S de Carapan, carretera 39, C. R. Bell y J. A. Duke 16700 (UC). Municipio de Coeneo: Coeneo, H. Díaz 6455 (IEB); Municipio de Huaniqueo: $5 \mathrm{~km}$ al S de Tendaparecua, J. Rzedowski 50361 (IEB). Municipio de Huiramba: Cerro Burro, 2400 m, J. M. Escobedo 745 (IEB). Municipio de La Piedad: Cujuarato, 2400 m, J. Rzedowski 45941 (IEB, UC). Municipio de Maravatío: km 97.5 carretera Atlacomulco - Morelia al W-SW de Maravatío, 2320 m, I. García y Y. Hernández 3540 (CIMI). Municipio de Morelia: $600 \mathrm{~m}$, al W de la Concepción, $2580 \mathrm{~m}, V$. M. Huerta 393 (EBUM); 9.5 km después de San Miguel del Monte hacia Túmbisca, $A$. Espejo 4893 (IEB); Cañada del Río Grande, cerca Cointzio, 1950 m, J. Rzedowski 45358 (IEB, UC); cerca del Puerto de los Copales, 2050 m, J. Rzedowski 40891 (ENCB, IEB); Cuanajillo, 2400 m, J. Rzedowski 49262 (IEB); El Resumidero, 2150 $\mathrm{m}$, J. Rzedowski 40425 (IEB); El Salto sobre carretera 15, $0.1 \mathrm{mi}$ al E de Temascal, E de Morelia, C. R. Bell y J. A. Duke 16714 (UC); km 15 carretera Morelia - Quiroga, J. I. Calzada 1564 (UC); Monte Rubio, J. M. Escobedo 2496 (IEB); Puerto del Tigre, km 29 carretera Morelia - Zamora, 2250 m, I. García 3251 (CIMI); San José de las Torres, 2300 m, J. Rzedowski 42154 (ENCB, IEB); Umécuaro, 2200 m, J. Rzedowski 47600 (IEB). Municipio de Pajacuarán: Barranca de Palo Alto, al S de Pajacuarán, 1850 m, I. García 4285 (CIMI). Municipio de Panindícuaro: volcán La Alberca, 2100 m, J. Rzedowski 40817 (ENCB, IEB). Municipio de Quiroga: Cerro Tzirate, $3000 \mathrm{~m}$, C. López 794 (IEB); $8.6 \mathrm{~km}$ E of Quiroga on hwy 15, $15 \mathrm{~km}$ of Morelia, $R$. Ornduff 8603 (ENCB, MEXU, UC). Municipio de Senguio: $4 \mathrm{~km}$ al SE de Senguio, M. Mejía 59 (IEB). Municipio de Tancítaro: Tancítaro, G. B. Hinton 15668 (UC). Municipio de Tzintzuntzan: frente a la colonia L. Cárdenas, 2100 m, H. Díaz 1902 (ENCB, IEB). Municipio de Uruapan: carretera Uruapan - Apatzingán $2.3 \mathrm{mi}$ al S de Uruapan, C. R. Bell y J. A. Duke 16687 (UC). Municipio de Yurécuaro: Yasque- 
ro, 2600 m, H. Díaz 3293 (IEB). Municipio de Zacapu: km 87 carretera 15 Morelia - Zamora, 2250 m, I. García 3088 (CIMI, UC); 1 km al E de la colonia Eréndira, 2100 m, I. García 3223 (CIMI, UC), 3059 (CIMI, UC). Municipio de Zamora: 4 km al S de Vista Hermosa, 2200 m, A. Martínez 349 (ENCB, IEB). Municipio de Zinapécuaro: $5 \mathrm{~km}$ al S de Jeráhuaro, $2350 \mathrm{~m}$, J. Rzedowski 46148 (IEB, UC); $5 \mathrm{~km}$ al S-SE de Jeráhuaro, 2550 m, J Rzedowski 46148 (CIMI, IEB); La Cañada, al E de El Rincón, 2450 m, M. J. Jasso 638 (CIMI, IEB); Las Peñas del Bellotal, H. Díaz 4238 (CIMI, IEB); Mesa Colmera, 2200 m, J. Martínez 1015 (ENCB, IEB, UC); Taimeo, $2100 \mathrm{~m}$, J. Rzedowski 46060 (IEB, UC).

\section{Eryngium mexiae Constance, Brittonia 32(2): 118-127. 1980.}

Hierba perenne, glabra, glauca, algo robusta; raíz gruesa, casi vertical, con un fascículo de raíces carnoso-fibrosas; tallos florales solitarios, de 0.5 a $2 \mathrm{~m}$ de alto, subescaposos; hojas basales rosuladas, ensiformes, generalmente dísticas, extendidas-ascendentes, linear-lanceoladas a linear-atenuadas, de 20 a $80 \mathrm{~cm}$ de largo y de 1.5 a $4.5 \mathrm{~cm}$ de ancho (incluyendo los lóbulos), de 0.7 a $2.5 \mathrm{~cm}$ sin ellos, espinoso-lobadas, los lóbulos lineares a lanceolado-subulados, de 3 a $20 \mathrm{~mm}$ de largo, divaricados a ascendentes, usualmente con una espínula auxiliar en la axila, las láminas rígidas, agudas en el ápice, en la base ligeramente expandidas dentro de una vaina desnuda tan ancha o más ancha que la lámina y de $3 \mathrm{a} 15 \mathrm{~cm}$ de largo, la venación paralela, las láminas de color verde fuerte arriba con una ligera banda central; hojas caulinares pocas, parecidas a las basales, alternas debajo de la inflorescencia, ascendentes o las del extremo superior algo recurvadas, fuertemente amplexicaules; inflorescencia cimoso-paniculada, 1 a 3 ramas fértiles, tricótomas rodeando y usualmente excediendo el pedúnculo terminal, a menudo complementados por ramas similares desde las axilas superiores; cabezuelas blanco-verdosas (o blanco-azulosas muy pálidas), ovoides a globosas, de 1 a $2 \mathrm{~cm}$ de largo y de 1 a 1.5 $\mathrm{cm}$ de ancho, largamente pedunculadas, glabras, con numerosas flores; brácteas del involucro 6 a 10, lineares o lanceolado-subuladas, de 0.5 a $2.5 \mathrm{~cm}$ de largo y de 2 a $5 \mathrm{~mm}$ de ancho, generalmente enteras, o con unos pocos dientes espinosos, extendidas o reflejas, usualmente más largas que las cabezuelas (ocasionalmente cortas); coma ausente; bractéolas lanceolado-subuladas, de 5 a $8 \mathrm{~mm}$ de largo, excediendo las flores; sépalos ovales, obtusos, mucronados o apiculados, de 1.5 a 2 mm de largo; pétalos oblongo-ovales, de 2 a $2.5 \mathrm{~mm}$ de largo, distalmente fimbriados; estilos de 3 a $4 \mathrm{~mm}$ de largo, excediendo los sépalos; fruto ovoide-cuneado, de $4 \mathrm{~mm}$ de largo (incluyendo los sépalos) y de 2 a $3 \mathrm{~mm}$ de ancho, comprimido dorsalmente, abaste- 
cido con una prominente hilera de escamas calicinas ovadas o lanceoladas, agudas, blancas o amarillentas con dos alas laterales de 3 o 4 escamas libres, la superficie dorsal desnuda.

Habitat, fenología y distribución geográfica. Eryngium mexiae crece en pastizales y laderas rocosas del bosque de encino, pino-encino y de coníferas, entre los 2000-3000 m de altitud. Florece de marzo a junio y fructifica de julio a febrero. Se conoce su distribución en Jalisco, Michoacán, Nayarit y Sinaloa. En Michoacán se registra de varias localidades de la Sierra del Centro.

Discusión. No se reportan nombres locales para esta especie. E. mexiae se relaciona morfológicamente con E. cymosum, en esta entidad. También se vincula con E. globosum y E. palmeri, que no se conocen de Michoacán, sin embargo E. mexiae presenta las hojas glaucas y usualmente dísticas, cabezuelas ovoides a globosas y la superficie dorsal del fruto es desnuda.

Ejemplares observados: Municipio de Angangueo: Llano del Toro, M. Mejia s.n. (IEB). Municipio de Aporo: Comunidad Juan Pérez, al S de Aporo, 2300 m, I. García 2704 (CIMI, IEB, UC). Municipio de Charo: entre el río de El Salto y la Polvilla, $18 \mathrm{mi}$ al E de Morelia, 7200-8000 ft, R. M. King y T. R. Soderstrom 5013 (MEXU). Municipio de Chilchota: Cerro Las Viudas y Las Torres, $2150 \mathrm{~m}, A$. Martínez 820 (ENCB, IEB); Ojo de Agua al S de Ocumicho, $2350 \mathrm{~m}, I$. García y J. Nava 3114 (CIMI). Municipio de Cotija: $0.5 \mathrm{~km}$ al S de Paredones, $2050 \mathrm{~m}$, I. García y G. Segura 3252 (CIMI); Agua de Maguey, 2300 m, I. García 3000 (CIMI, IEB, UC); Paredones, al S de Jiquilpan, 2000 m, I. García 2171 (CIMI, IEB). Municipio de Indaparapeo: $10 \mathrm{~km}$ al N de Indaparapeo, $2250 \mathrm{~m}$, J. Rzedowski 42322 (ENCB, IEB); $11 \mathrm{~km}$ al N de Indaparapeo, sobre el camino a Las Peras, $2200 \mathrm{~m}$, J. Rzedowski 43220 (IEB). Municipio de Jiquilpan: Cerro La Viña, 2000 m, I. García 2958 (CIMI, IEB, UC); Cerro Santa María al SW de Jiquilpan, 2000 m, C. Feddema 156 (ENCB, UC). Municipio de Marcos Castellanos: Los Trigos al SW de La Arena, 2220 m, I. García et al. 3118 (CIMI, UC). Municipio de Morelia: N del Pico Azul, 2300 m, J. Rzedowski 42138 (ENCB); San José de Las Torres, 2300 m, J. Rzedowski 42138 (ENCB, IEB). Municipio de Nahuatzen: aproximadamente $7 \mathrm{~km}$ carretera San Isidro - entronque Zinziro - Erongarícuaro, 2300 m, I. García 3854 (CIMI). Municipio de Nuevo Parangaricutiro: $1-1.5 \mathrm{~km}$ al W del Tejamanil, $2600 \mathrm{~m}$, I. García et al. 4585 (CIMI). Municipio de Paracho: km 46.5 carretera Carapan - Uruapan, 2250 m, I. García y Y. Hernández 3454 (CIMI), 3017 (CIMI, IEB, UC). Municipio 
de Pátzcuaro: 18 mi S of Pátzcuaro, 8900-9000 ft, R. M. King y T. R. Soderstrom 5172 (UC); Cerro Los Lobos, 2300 m, H. Díaz 1940 (ENCB, IEB). Municipio de Tingambato: Cerro San Juan desviación a Zirahuén, 2400 m, H. Díaz 2074 (CHAP, IEB, UC); L. M. Chávez 65 (IEB, UC). Municipio de Tlalpujahua: $5 \mathrm{~km}$ SE de Tlalpujahua, camino a El Oro, $2850 \mathrm{~m}$, J. Rzedowski 42257 (IEB). Municipio de Uruapan: $2 \mathrm{~km}$ al SE de Angahuan, $2250 \mathrm{~m}$, I. García y Y. Hernández 3722 (CIMI). Municipio de Villa Jiménez: Cerro La Alberca, 2600 m, E. Pérez 1091 (EBUM, IEB). Municipio de Zinapécuaro: $6 \mathrm{~km}$ al S-SW de Ucareo, $2300 \mathrm{~m}$, I. García 3009 (CIMI, IEB, UC); km 14 carretera 51 Huajúmbaro - Zinapécuaro, 2500 m, I. García 2722 (CIMI, IEB, UC); Los Azufres, 2950 m, E. Carranza 366 (EBUM, IEB); Sierra de Zinapécuaro, $16 \mathrm{~km}$ al NE de Queréndaro, C. Jiménez 265 (ENCB, UC); Taimeo El Chico, 2400 m, J. Rzedowski 42359 (ENCB, IEB); W del Cerro Mozo, 2450 m, M. J. Jasso 880 (IEB); W del Cerro San Andrés, 2850-3000 m, R. McVaugh 9876 (UC).

14. Eryngium mexicanum S. Wats., Proc. Amer. Acad. Arts 26: 136. 1891.

E. fluitans M. E. Jones 1908.

E. wolffii Mathias 1929.

Hierba perenne, glabra, delgada, caulescente; raíces fasciculadas, fibrosas, blandas; tallos varios, de 15 a 40(80) cm de alto, fistulosos, débilmente erectos o ascendentes, ramificados; hojas basales lineares a lanceoladas, de 2 a $15 \mathrm{~cm}$ de largo y de 0.5 a $3 \mathrm{~cm}$ de ancho, enteras a o pinnatisectas, los lóbulos lineares o lanceolados, enteros o escasamente aserrados, de $1 \mathrm{a} 2 \mathrm{~cm}$ de largo, la venación pinnadamente reticulada; pecíolos fistulosos y septados, envainándose anchamente en la base, de 5 a 10(40) cm de largo, excediendo con mucho las láminas; hojas caulinares de hasta 15 $\mathrm{cm}$ de largo incluyendo el pecíolo, similares a las basales, enteras a ternadas o pinnadamente partidas con divisiones herbáceas alargadas, débiles, las hojas superiores sésiles y opuestas; inflorescencia sucesivamente trifurcada o cimosa, las cabezuelas, numerosas, pedunculadas; cabezuelas azules, ovoide-cilíndricas, de 10 a $15 \mathrm{~mm}$ de largo, de 6 a $8 \mathrm{~mm}$ de diámetro, con numerosas flores; se ha observado en algunos materiales la tendencia de las cabezuelas a separarse o dividirse en dos; brácteas del involucro 8 a 12(15), rígidas, extendidas, linear-lanceoladas a lanceoladas, de 10 a $15 \mathrm{~mm}$ de largo y de 2 a $3 \mathrm{~mm}$ de ancho, pungentes, enteras o con un par de espinas inconspicuas, verdes en el envés y de color blanco-crema en el haz, más cortas o excediendo el largo de las cabezuelas; bractéolas subuladas, de 2 a $3 \mathrm{~mm}$ de largo, enteras, excediendo el largo del fruto; coma de una bractéola simple bi o trilobada, filiforme hacia la punta o parte media, de 15 a $25 \mathrm{~mm}$ de largo (tan larga o más larga 
que la cabezuela); sépalos ovados, de cerca de $0.5 \mathrm{~mm}$ de largo, obtusos, apiculados en el ápice; pétalos espatulados, de 0.6 a $0.8 \mathrm{~mm}$ de largo; estilos delgados, de 0.6 $\mathrm{mm}$ de largo; fruto ovoide, de $1 \mathrm{a} 2 \mathrm{~mm}$ de largo y de $1.5 \mathrm{~mm}$ de ancho, densamente cubierto con abundantes escamas desiguales, lanceoladas o piramidales, blancas.

Habitat, fenología y distribución geográfica. Eryngium mexicanum habita en pastizales húmedos e inundables de planicies y claros del bosque de encino, pinoencino y de coníferas, entre los 2250-2700 m de altitud. Florece de julio a agosto y fructifica de septiembre a noviembre. Se conoce su distribución en Chihuahua, Durango, Estado de México, Michoacán y Morelos. En Michoacán se conoce de algunas localidades de la Sierra del Centro.

Discusión. No se conocen reportes de nombres locales para E. mexicanum. En cuanto a su morfología y hábito $E$. mexicanum puede relacionarse con $E$. phyteumae, sin embargo las brácteas del involucro de E. mexicanum son extendidas y el coma está formado por una sola bractéola, el color de la cabezuela es café claro a blanquecino en contraste con la cabezuela y coma de color azul de E. phyteumae.

Ejemplares observados: Municipio de Salvador Escalante: La Lagunita, ca. San Gregorio, 2700 m, J. Rzedowski 44646 (CIMI, IEB, UC); San Gregorio, H. Díaz 3426 (IEB); San Gregorio, 2250 m, J. M. Escobedo 496 (ENCB, IEB). Municipio de Zinapécuaro: $1 \mathrm{~km}$ al E de la desviación a Ucareo, carretera Maravatío - Morelia, 2350 m, I. García y Y. Hernández 3544 (CIMI); 2 km al N de Jeráhuaro, 2360 m, I. García et al. 3664 (CIMI); El Llanito, $500 \mathrm{~m}$ al SW de Jeráhuaro, M. J. Jasso 403 (CIMI, IEB); lado NW de Jeráhuaro, cerca de la carretera Morelia - Maravatío, 2467 m, I. García et al. 8369 (CIMI).

15. Eryngium monocephalum Cav., Anal. Hist. Nat. 2: 116. 1800.

E. bromeliaefolium Delar. 1808.

E. involucratum Coult. \& Rose 1895.

Hierba perenne, glabra, erecta, rígida; raíces carnosas, fasciculadas; tallo único de 0.5 a $1.2 \mathrm{~m}$ de alto, a veces ramificado; hojas basales dispuestas en roseta, linear-lanceoladas, de 10 a $50 \mathrm{~cm}$ de largo y de 0.5 a $2.5 \mathrm{~cm}$ de ancho, ligeramente atenuadas hacia la base, margen espinoso-aserrado, con los dientes extendidos o ascendentes, de 5 a $30 \mathrm{~mm}$ de largo, ápice acuminado, venación paralela; hojas caulinares semejantes a las basales, pero de menores dimensiones, recurvadas, sésiles, 
alternas o a veces las superiores opuestas, cada una de las espinas del borde con frecuencia acompañada de otras más cortas; cabezuela por lo general solitaria, terminal, acompañada a veces con 1 o 2 axilares; cabezuelas ovoides a globosas, de 1 a $2.5(4) \mathrm{cm}$ de largo y de 1 a $1.5(2.5) \mathrm{cm}$ de diámetro, con numerosas flores; brácteas del involucro 12 a 30, biseriadas, imbricadas, rígidas, ascendentes, lineares a lanceoladas, de 3 a $8 \mathrm{~cm}$ de largo y de 3 a $10 \mathrm{~mm}$ de ancho, de margen y ápice espinosos, con frecuencia excediendo y encerrando la cabezuela; bractéolas lanceoladas, de 4 a $6 \mathrm{~mm}$ de largo, apiculadas, más largas que el fruto; coma ausente; sépalos ovados a lanceolados, de 2 a $4 \mathrm{~mm}$ de largo, mucronados; pétalos de 2 a $3 \mathrm{~mm}$ de largo; estilos de 3 a $5 \mathrm{~mm}$ de largo; fruto cilíndrico, cuneado, de 3 a $5 \mathrm{~mm}$ de largo y de $2.5 \mathrm{~mm}$ de ancho, escamas laterales evidentes, ovadas, prolongándose hacia abajo en una ala estrecha, a veces interrupta.

Habitat, fenología y distribución geográfica. Eryngium monocephalum crece en claros y áreas sombreadas del bosque de coníferas, entre los 3100-3500 m de altitud. Florece y fructifica de julio a octubre. Se conoce su distribución en Hidalgo, Michoacán, Puebla, Oaxaca y Veracruz. En Michoacán se registra de dos localidades en la Sierra del Centro.

Discusión. No se reportan nombres locales para esta especie. E. monocephalum se relaciona morfológicamente y en hábito con E. alternatum y E. proteaeflorum, sin embargo el primero tiene una longitud de su tallo floral de hasta $1.2 \mathrm{~m}$, lo que constituye un porte intermedio entre los otros dos, así como hojas del tallo recurvadas y una cabezuela ovoide hasta de aproximadamente $4 \mathrm{~cm}$ de largo y hasta de $2.5 \mathrm{~cm}$ de ancho.

Ejemplares observados: Municipio de Angangueo: Reserva de la Mariposa Monarca Las Papas, Sierra de Chincua, lado SW, 3365 m, I. García y M. Costea 8418 (CIMI). Municipio de Zinapécuaro: ladera SW del Cerro San Andrés, 3200 m, S. Zamudio 5524 (IEB); Cerro San Andrés, lado W, 3070 m, M. J. Jasso 591 (IEB); parte alta del Cerro San Andrés, 3430 m, S. Zamudio y E. Pérez 7093 (IEB).

\section{Eryngium phyteumae Delar. f., Eryng. 51 t. 21. 1808.}

E. cylindraceum (cylindricum) Willd. 1825.

E. horminoides DC. 1830.

E. phyteumatos Benth. 1840.

E. discolor S. Wats. 1883. 
Hierba perenne, glabra, más bien delgada, caulescente; raíces fasciculadas blando-fibrosas; tallos solitarios o pocos, de 30 a $70 \mathrm{~cm}$ de alto, simples o escasamente ramificados; hojas oblongas a lanceoladas, de 6 a $20 \mathrm{~cm}$ de largo y de 1 a 2 $\mathrm{cm}$ de ancho, redondeadas a cuneadas en la base, apiculadas, obscuramente crenadas o crenado-aserradas, la venación reticulada; pecíolos fistulosos, septados, de 7 a $18 \mathrm{~cm}$ de largo; hojas caulinares semejantes a las basales, las superiores sésiles; inflorescencia simple o en forma de cima poco ramificada, las cabezuelas pocas ( 1 a 6), pedunculadas; cabezuelas de color azul fuerte, ovoide-cilíndricas, de 1 a $2 \mathrm{~cm}$ de largo y de 8 a $12 \mathrm{~mm}$ de ancho, flores numerosas; brácteas del involucro 6 a 10, reflejas, linear-lanceoladas, de 1 a $4 \mathrm{~cm}$ de largo y de 2 a $3 \mathrm{~mm}$ de ancho, agudas, enteras a escasamente espinuloso-serradas, verdes abajo y blancas o azules arriba, tan largas o excediendo las cabezuelas; bractéolas subuladas, de 3 a $5 \mathrm{~mm}$ de largo, excediendo el largo de los frutos; coma de 3 a 5 bractéolas enteras o espinulososerradas, de 5 a $15 \mathrm{~mm}$ de largo; sépalos anchamente ovados, mucronados, obtusos a truncados de 1.2 a $1.6 \mathrm{~mm}$ de largo; pétalos oblongos u oblanceolados, de 1 a 1.5 $\mathrm{mm}$ de largo; estilos delgados, de 1.3 a $1.8 \mathrm{~mm}$ de largo; fruto ovoide, de 2 a $3 \mathrm{~mm}$ de largo y de $1.4 \mathrm{~mm}$ de ancho, densamente cubierto con escamas planas, lanceoladas, blancas a traslúcidas, subiguales.

Habitat, fenología y distribución geográfica. Eryngium phyteumae crece en lugares de suelo húmedo e inundado del pastizal en medio del bosque tropical caducifolio y bosque de coníferas, entre los 1750-2550(3250) m de altitud. Florece y fructifica de julio a noviembre. Se conoce su distribución de Arizona en Estados Unidos de América a Chihuahua, Estado de México y Michoacán. En este último estado se registra de varias localidades de la Sierra del Centro.

Discusión. No se conocen reportes de nombres locales para esta especie. $E$. phyteumae se relaciona en hábito y morfología con $E$. mexicanum, sin embargo $E$. phyteumae presenta un menor número de brácteas del involucro (6 a 10) y su coma está formado por varias bractéolas subiguales, también el color azul de sus cabezuelas es un rasgo muy distintivo.

Ejemplares observados: Municipio de Hidalgo: route $15 \mathrm{ca} .23 .5 \mathrm{~km}$ al W of Ciudad Hidalgo, $2300 \mathrm{~m}, R$. W. Cruden 1345 (INIF, UC). Municipio de Morelia: 2 km al S de Umécuaro, 2000 m, J. Rzedowski 42987 (IEB), 47594, (IEB); Umécuaro, H. Díaz 6265 (IEB). Municipio de Tlalpujahua: al SE de San Francisco de los Reyes, 2550 m, I. García y Y. Hernández 3523 (CIMI); aprox. 1 km al SE de San Francisco 
de los Reyes, 2615 m, I. García y M. García 8357 (CIMI); carretera Santa María - San José de Guadalupe, $4 \mathrm{~km}$ al SE de San Francisco de los Reyes, $2500 \mathrm{~m}$, I. García y $Y$. Hernández 3555, 4884 (CIMI); San Francisco de los Reyes, 2600 m, I. García 3229 (CIMI, UC). Municipio de Zacapu: hwy 15 at km 387, 3 mi SW of Naranja, $7100 \mathrm{ft}$, E. Molseed 233 (MEXU, UC). Municipio de Zinapécuaro: $1 \mathrm{~km}$ de la desviación a Jeráhuaro - Zinapécuaro, H. Díaz 6812 (IEB); El Llanito, al W de Jeráhuaro, $2460 \mathrm{~m}$, M. J. Jasso 1395, 1646 (IEB, MEXU); Jeráhuaro, 2350 m, M. J. Jasso 405 (IEB), 1395 (IEB); presa Laguna Larga, 2970 m, H. Díaz y S. Zamudio 2731 (CHAP, EBUM, IEB). Municipio de Zitácuaro: Zitácuaro-Zirahuate, 1950 m, G. B. Hinton 13123 (UC).

17. Eryngium proteaeflorum Delar., Eryng. 62. pl. 30. 1808. E. seatonii Coult. \& Rose 1893.

Hierba perenne, glabra, caulescente, erecta, rígida y más bien robusta; raíces fasciculadas; tallo solitario, de 0.5 a $1 \mathrm{~m}$ de alto, a veces ramificado; hojas inferiores dispuestas en roseta apretada a algo laxa, linear-lanceoladas, de 10 a $30 \mathrm{~cm}$ de largo y de 1 a 2.5(6) $\mathrm{cm}$ de ancho, más anchas cerca de la parte media, base cortamente envainante, margen espinoso-lobado con las espinas extendidas o ascendentes, de 5 a $20 \mathrm{~mm}$ de largo, ápice agudo con una espina en la punta, nervación paralela; hojas caulinares alternas, ascendentes, semejantes a las basales, cada una de las espinas lisas del borde con frecuencia acompañada de otra más corta; cabezuela por lo común solitaria, terminal, a veces también con 1 o 2 axilares; cabezuelas ovoide-cilíndricas, moradas, de 2 a $6 \mathrm{~cm}$ de largo y de 1.5 a $3 \mathrm{~cm}$ de ancho, con numerosas flores; brácteas del involucro 15 a 30, dispuestas en 2 a muchas series, imbricadas, rígidas, ascendentes, lineares a lanceoladas, de 5 a $12 \mathrm{~cm}$ de largo y de 5 a $20 \mathrm{~mm}$ de ancho, las internas más pequeñas y estrechas, con las puntas y los bordes espinosos o enteros, sobrepasando y encerrando a las cabezuelas; bractéolas linear-lanceoladas, de 5 a $8 \mathrm{~mm}$ de largo, espinosas en el ápice, más largas que el fruto; coma generalmente ausente, a veces varias bractéolas presentan mayor desarrollo cerca del ápice y dan la apariencia de coma corto e inconspicuo; sépalos anchamente ovados, apiculados, de 2 a $3 \mathrm{~mm}$ de largo; pétalos obovados, de $2 \mathrm{~mm}$ de largo; estilos de 2 a $3 \mathrm{~mm}$ de largo; fruto cuneado-cilíndrico, de 3 a $5 \mathrm{~mm}$ de largo y de 2 a $3 \mathrm{~mm}$ de ancho, desnudo, excepto unas cuantas escamas aplanadas, lanceoladas, aparentando un pequeño cáliz, colocadas en el ápice de los ángulos.

Habitat, fenología y distribución geográfica. Eryngium proteaeflorum se encuentra en el pastizal alpino y áreas abiertas del bosque de coníferas; entre los 3000$3800 \mathrm{~m}$ de altitud. Florece y fructifica de julio a octubre. Se conoce su distribución 
en partes altas de las montañas del Eje Neovolcánico Transversal, de el Pico de Orizaba en Veracruz, el Popocatépetl, el Iztaccíhuatl y el Nevado de Toluca en el Estado de México y en Michoacán. En este último estado son escasos los registros, se conoce de dos localidades en la Sierra del Centro.

Discusión. En la literatura se reporta el nombre de cardo santo para esta especie (Estado de México y Valle de México). E. proteaeflorum se relaciona en hábito y morfología con E. monocephalum, sin embargo E. proteaeflorum generalmente es de menor tamaño y más robusta; suelen desarrollarse varios individuos juntos (en macollos), presenta la cabezuela de mayor tamaño de las especies, brácteas grandes y anchas de color crema plateado, y la cabezuela morada con un fuerte olor a materia fecal.

Ejemplares observados: Municipio de Hidalgo: parte alta Cerro San Andrés, ca. $12 \mathrm{~km}$ (línea recta) al N de Ciudad Hidalgo, J. H. Beaman 4292 (UC); cima del Cerro San Andrés, alrededor de las antenas, 3568 m, G. Aguilar et al. 806 (IEB). Municipio de Maravatío: lado NW del Cerro San Andrés, $3000 \mathrm{~m}$, I. García et al. 3661 (CIMI).

18. Eryngium serratum Cav., Anal. Hist. Nat. 2: 132. 1800.

E. schiedeanum Cham. \& Schlecht. 1830.

Hierba perenne, glabra, delgada, erecta; raíces fasciculadas, leñoso-fibrosas; tallos solitarios, de 20 a $80 \mathrm{~cm}$ de alto, ramificándose en la parte media; hojas basales coriáceas; pecíolos algo alados, ampliamente envainantes en la base, de 2 a $20 \mathrm{~cm}$ de largo, láminas lanceoladas a oblongas, de 4 a $15 \mathrm{~cm}$ de largo, ápice agudo u obtuso, margen calloso, espinuloso-aserrado o dentado a subpinnatífido, base cuneada, venación pinnadamente reticulada; hojas caulinares pocas, las superiores muy reducidas, sésiles, incisas a lobadas; inflorescencia cimosa, de pocas cabezuelas pedunculadas; cabezuelas verdosas, amarillentas o blanquecinas, subglobosas a ovoide-cilíndricas, de 5 a $20 \mathrm{~mm}$ de largo y de 6 a $12 \mathrm{~mm}$ de ancho, con numerosas flores; brácteas del involucro 8 a 12, rígidas, ascendentes, linear-lancelodas, de 5 a $10 \mathrm{~mm}$ de largo y de 1 a $2 \mathrm{~mm}$ de ancho, agudas, enteras o con 1 o 2 dientes espinosos, verdosas en ambas caras, más cortas que las cabezuelas; bractéolas subuladas, de 5 a $6 \mathrm{~mm}$ de largo, escarioso-aladas en la base, más largas que el fruto; coma generalmente ausente o muy poco desarrollado; sépalos estrechamente lanceolados, de 2 a $3 \mathrm{~mm}$ de largo, mucronados; pétalos oblongos, de 1.5 a $2 \mathrm{~mm}$ de largo; estilos delgados, de 2.5 a $3.2 \mathrm{~mm}$ de largo; fruto ovoide, de 2 a $3 \mathrm{~mm}$ de largo y de 1 a $2 \mathrm{~mm}$ 
de ancho, densamente cubierto por escamas blancas de hasta $1 \mathrm{~mm}$ de largo, lanceolado-acuminadas, las laterales y las de la base del cáliz, más largas que el resto.

Habitat, fenología y distribución geográfica. Eryngium serratum crece en áreas abiertas y sombreadas del matorral bajo espinoso, bosque de encino y de pino-encino, entre los 2100-2700 m de altitud. Florece de junio a julio, fructifica de agosto a enero. Se conoce su distribución en el Distrito Federal, Estado de México, Guanajuato, Hidalgo, Michoacán, Nuevo León, San Luis Potosí, Tamaulipas y Veracruz. En Michoacán se registra del noreste, en la Sierra del Centro.

Discusión. No se conocen reportes sobre nombres locales para este taxon. $E$. serratum en realidad no se relaciona con ninguna especie de esta entidad federativa; sin embargo, en cuanto al hábitat en que se desarrolla podría ser confundida en primer instancia con E. comosum, una vez que se ha desarrollado por completo la planta es evidente el tallo erecto, simple (a veces más de uno) y un coma y brácteas enteras poco desarrolladas de E. serratum. Por otro lado algunos materiales de $E$. gracile con brácteas poco desarrolladas se han confundido con E. serratum, sobre todo por la apariencia del borde aserrado en las hojas del tallo.

Ejemplares observados: Municipio de Epitacio Huerta: $0.5 \mathrm{~km}$ al NW de Epitacio Huerta, 2450 m, I. García y A. García 3234 (CIMI); cerca poblado La Paz, $2200 \mathrm{~m}$, H. Díaz y E. Pérez 6040 (CIMI, IEB); La Cima, $7 \mathrm{~km}$ al W de Amealco, $2650 \mathrm{~m}$, J. Rzedowski 44603 (IEB). Municipio de Maravatío: Las Palmas, Santa Mónica, 2360 m, S. Zamudio 5385 (IEB); km 94.8, carretera 126 al W-SW de Maravatío, 2340 m, I. García 3095 (CIMI, UC), 3212 (CIMI), 3227 (CIMI), I. García y Y. Hernández 3535 (CIMI). Municipio de Tlalpujahua: $2 \mathrm{~km}$ al W de Tlacotepec, al NE de Tlalpujahua, 2550 m, I. García y Y. Hernández 3536, 6134 (CIMI); lado NE de Tlapujahua, 2624 m, I. García y M. García 8367 (CIMI). Municipio de Zinapécuaro: $2 \mathrm{~km}$ al E de Jeráhuaro, camino a Huajúmbaro, $2380 \mathrm{~m}$, M. J. Jasso 254 (IEB); Cerro El Copetón, 1 km al NW de Buenavista, 2390 m, M. J. Jasso 348 (EBUM, IEB); El Cerrito al W de Jeráhuaro, 2520 m, M. J. Jasso 1706 (IEB); El Roblar, $5 \mathrm{~km}$ al SW de Jeráhuaro, 2380 m, M. J. Jasso 576 (IEB).

19. Eryngium sparganophyllum Hemsl., in Hook. Ic. 26: t. 2508. 1897.

Hierba perenne, glabra, caulescente; raíz gruesa tuberosa con un fascículo de raíces fibrosas; tallo solitario o varios de 0.4 a $1.20 \mathrm{~m}$ de alto, erectos; hojas basales 
numerosas, lineares a linear-lanceoladas, de 10 a $90 \mathrm{~cm}$ de largo y de 5 a $15 \mathrm{~mm}$ de ancho, más anchas hacia la base, atenuadas hacia el ápice, enteras o escasamente espinuloso-dentadas con dientes de $2 \mathrm{~mm}$ o menos de largo, sin espinas axilares, venación paralela, vaina o base del pecíolo que rodea al tallo más ancha que la lámina de la hoja, semicircular o plana, de 2 a $10 \mathrm{~cm}$ de largo; hojas caulinares, pocas, parecidas a las basales pero reducidas y sésiles, las inferiores alternas, las superiores opuestas; inflorescencia divaricadamente cimosa o trifurcada, raramente reducida a una sola cabezuela; cabezuelas largas, numerosas o escasas, pedunculadas, azules, ovoides a ovoide-oblongas, de 15 a $25 \mathrm{~mm}$ de largo y de 10 a $15 \mathrm{~mm}$ de ancho, redondeadas en la base, con numerosas flores; brácteas del involucro 8 a 12, herbáceas, débilmente extendidas a reflejas, lineares, de 5 a $15 \mathrm{~mm}$ de largo, pungentes, enteras, más cortas que las cabezuelas; bractéolas lanceoladas, de $5 \mathrm{~mm}$ de largo, curvadas, pungentes, enteras, excediendo el fruto; coma ausente; sépalos ovados, de 1.5 a $2 \mathrm{~mm}$ de largo, obtusos, apiculados; pétalos oblongos, de cerca de $2 \mathrm{~mm}$ de largo; estilos delgados, excediendo a los sépalos; fruto ovoide, de 3 a $4 \mathrm{~mm}$ de largo, las escamas del caliz con los ángulos lanceolados de hasta $1 \mathrm{~mm}$ de largo, superficie algo papilosa.

Habitat, fenología y distribución geográfica. Eryngium sparganophyllum crece en áreas del sotobosque del bosque pino-encino y en pastizales abiertos, entre los 2100$2500 \mathrm{~m}$ de altitud. Florece y fructifica de octubre a enero. Se conoce su distribución de Nuevo México y Arizona en Estados Unidos de América a Durango, Jalisco y Michoacán, en esta última entidad se encuentra en dos localidades de la Sierra del Centro.

Discusión. No se reportan nombres locales para E. sparganophyllum. Esta especie se encuentra relacionada en hábito y morfología con E. longifolium, sin embargo se separa de ésta en que las hojas de E. sparganophyllum no presentan espinas laterales de las hojas o éstas son muy escasas y las cabezuelas son de color azul y más redondeadas hacia la base.

Ejemplares observados: Municipio de Erongarícuaro: Cerro Huacapían, 2100 m, H. Díaz 1871 (ENCB, IEB, UC). Municipio de Zinapécuaro: La Cañada, al E del Rincón, 2450 m, M. J. Jasso 638 (IEB).

20. Eryngium spiculosum Hemsl., in Hook., Ic. 26: t. 2507. 1897.

Hierba perenne, glabra; raíz fasciculada, fibrosa; tallos erectos hasta de $1 \mathrm{~m}$ de alto, ramificados; hojas basales delgadas, oblongas a obovadas, de 5 a $15 \mathrm{~cm}$ de largo y 
de 1.5 a $3 \mathrm{~cm}$ de ancho, largamente cuneadas en la base, ápice obtuso, calloso-marginadas, crenado-aserradas, la venación pinnadamente reticulada; pecíolos delgados, envainantes y alados hacia la base, de 2 a 5(9) cm de largo, tan largos o más cortos que las láminas; hojas del tallo sésiles, anchas, envainantes, generalmente alternas, de 15 a 25 $\mathrm{cm}$ de largo, palmadamente partidas con lóbulos lanceolados, las superiores de menor longitud; inflorescencia divaricadamente trifurcada, las ramas laterales alargadas en forma de monocasio, las cabezuelas pequeñas, numerosas, pedunculadas, pediceladas; cabezuelas globoso-ovoides, de 6 a $8 \mathrm{~mm}$ de largo y de 5 a $6 \mathrm{~mm}$ de ancho, con numerosas flores; brácteas del involucro 5 a 6(-8?), reflejas, lanceoladas a linear-lanceoladas, desiguales, de 12 a $25 \mathrm{~mm}$ de largo y de 2 a $4 \mathrm{~mm}$ de ancho, acuminadas, espinosas en el ápice, pungentes, enteras, envés verde y verdes a blanquecinas hacia la base en el haz, más largas que las cabezuelas; bractéolas subuladas, de 3 a $4 \mathrm{~mm}$ de largo, enteras, excediendo el fruto; coma de 1 o 2 bractéolas, de 10 a $15 \mathrm{~mm}$ de largo, similares a las brácteas; sépalos ovados, de $1.5 \mathrm{~mm}$ de largo, obtusos, mucronulados, los márgenes escariosos; pétalos oblanceolados, de cerca de $1 \mathrm{~mm}$ de largo; estilos delgados, de 1.7 $\mathrm{mm}$, excediendo los sépalos; fruto globoso a algo alargado, de 1 a $2 \mathrm{~mm}$ de largo y de $1 \mathrm{a} 1.5 \mathrm{~mm}$ de ancho, densamente cubierto de escamas blandas, papilosas, setiformes.

Habitat, fenología y distribución geográfica. Eryngium spiculosum crece en las orillas de arroyos y lugares arenosos y sombreados del bosque tropical caducifolio y el encinar tropical, entre los 1000-1300 m de altitud. Florece y fructifica de enero a marzo. Se conoce su distribución en los estados de Morelos, Guerrero y Michoacán. En Michoacán se conoce de dos localidades en la región de la Tierra Caliente y Sierra del Centro.

Discusión. Se conoce localmente con el nombre de hierba del sapo. E. spiculosum se relaciona morfológicamente con E. heterophyllum y E. beecheyanum, ya que se podrían confundir en estadio juvenil, sin embargo el habitat en que crece es E. spiculosum es muy diferente, pues mientras E. heterophyllum se desarrolla en lugares abiertos de ambientes secos y E. beecheyanum en pastizales; E. spiculosum crece en lugares sombreados de ambientes más húmedos; en cuanto al porte, esta última es más delgada, débilmente erecta y presenta menos espinas en sus hojas, sus brácteas son lanceoladas, terminan en una espina fina y sus frutos están densamente cubiertos por papilas alargadas setiformes muy distintas a las del resto del grupo.

Ejemplares observados: Municipio de Ario de Rosales: $1 \mathrm{mi}$ E of El Cangrejo, 11 miles N of La Huacana, A. Liston, O. Dorado y D. M. Arias 632-6 (UC); km 
26.5 carretera Ario de Rosales - La Huacana, 1180 m, I. García y S. Zamudio 3363 (CIMI). Municipio de Jiquilpan: (cultivada del número 3363), $1550 \mathrm{~m}$, I. García 3402 (CIMI, UC). Municipio de Taretan: aprox. $2 \mathrm{~km}$ al noreste de Taretan, base suroeste del Cerro El Cobrero, 1300 m, Y. Ramírez Amezcua y V. W. Steinmann 834 (IEB).

\section{Eryngium subacaule Cav., Anal. Hist. Nat. t. 556, f. 2. 1801.} E. ranunculoides Benth. 1839.

Hierba perenne, glabra, subacaule; raíces fasciculadas; tallos uno o varios, delgados, erectos, de 5 a $35 \mathrm{~cm}$ de alto, con frecuencia se dividen cerca de la base; hojas basales con pecíolos anchamente alados, envainantes en la base, ovadas $\mathrm{u}$ oblongas a linear-lanceoladas, de 1 a $6 \mathrm{~cm}$ de largo y de 5 a $18 \mathrm{~mm}$ de ancho, ápice obtuso o agudo, margen entero a crenado-aserrado, calloso, venación reticulada, pecíolo de 3 a $8 \mathrm{~cm}$ de largo; hojas caulinas escasas, opuestas, sésiles, semejantes a las basales, pero más reducidas; cabezuelas solitarias sobre un pedúnculo que es la continuación del tallo, de color azul-violáceo, ovoides o subglobosas, de 5 a 13 $\mathrm{mm}$ de largo y de 4 a $10 \mathrm{~mm}$ de diámetro, flores numerosas; brácteas del involucro 7 a 10, ampliamente lanceoladas, de 10 a $15 \mathrm{~mm}$ de largo y de 2 a $3 \mathrm{~mm}$ de ancho, apiculadas, margen entero o provisto de 1 o 2 espínulas, calloso, la cara abaxial suele ser de color verde o a veces azul en la base, venosa y la adaxial plateada, blanquecina, azulosa o violácea; bractéolas lanceoladas, de 2 a $3 \mathrm{~mm}$ de largo; coma ausente; sépalos ampliamente lanceolados, de alrededor de $1.5 \mathrm{~mm}$ de largo, mucronados; pétalos del mismo tamaño que los sépalos; estilos de $1.6 \mathrm{~mm}$ de largo; fruto globoso, de aproximadamente $2 \mathrm{~mm}$ de largo y $1.3 \mathrm{~mm}$ de ancho, cubierto por unas cuantas (5 o 6) escamas anchamente lanceoladas en la base del cáliz, en el resto del fruto varias más, de menor tamaño.

Habitat, fenología y distribución geográfica. Eryngium subacaule es frecuente encontrarlo en el pastizal o bien cerca de arroyos, en lugares de suelo húmedo e inundable y terrenos abiertos del bosque de coníferas, entre los 2700-3250 m de altitud. Florece y fructifica de mayo a octubre. Se conoce su distribución en los estados de México, Michoacán y Morelos. En Michoacán se ha colectado en la Sierra del Centro.

Discusión. Esta especie no presenta registros de nombres locales. E. subacaule por su hábito y suculencia se puede relacionar con E. phyteumae; en cuanto 
a su morfología, se distingue principalmente en que la primera presenta hojas con venación reticulada, cabezuelas más cortas y carece de coma.

Ejemplares observados: Municipio de Angangueo: alrededores del Llano de Las Papas, 3200 m, J. Rzedowski 47360, 47369 (IEB, MEXU); Las Papas, Sierra de Chincua, 3100 m, I. García 1998 (CIMI, IEB), I. García y M. García 2369 (CIMI, IEB), 3238 (CIMI, UC), I. García y Y. Hernández 3558 (CIMI); Llano de Las Papas, 3250 m, I. García y M. García 8365 (CIMI). Municipio de Salvador Escalante: La Laguna, San Gregorio, 2700 m, I. García y S. Zamudio 2338-B (CIMI, IEB). Municipio de Zinapécuaro: $1 \mathrm{~km}$ al NE de Laguna Larga, Los Azufres, $2800 \mathrm{~m}, I$. García 2941 (CIMI, IEB); Llano de los Ajolotes, Los Azufres, 2470 m, M. J. Jasso 1236 (IEB).

\section{CONCLUSIONES Y PERSPECTIVAS EN EL ESTUDIO DEL GÉNERO ERYNGIUM EN MICHOACÁN}

Distribución reportada de las especies de Eryngium en México

De acuerdo con la información proporcionada por varios autores sobre las especies de Eryngium, se considera que E. beecheyanum, E. carlinae, E. ghiesbreghtii, E. gracile, E. heterophyllum y E. serratum presentan una amplia distribución, ya que se reportan de numerosas entidades federativas de la República Mexicana. Algo similar, pero menos frecuentes son E. alternatum, E. bonplandii, E. columnare, E. longifolium y E. mexiae, que se conocen de algunos estados del país. Por otra parte, E. monocephalum y E. proteaeflorum, restringen su área a las partes altas del Eje Volcánico Transversal. A su vez E. mexicanum, E. phyteumae y E. sparganophyllum muestran una distribución disyunta, presentándose en la porción sur de Estados Unidos de América y al norte-centro de México. Por último las especies E. cervantesii, E. comosum, E. cymosum, E. spiculosum y E. subacaule habitan en el sector centro-occidente de México, considerándose endemismos de esta región.

Distribución de las especies de Eryngium en el estado de Michoacán

El género Eryngium se encuentra bien representado en el estado de Michoacán. Sus especies se distribuyen en varios tipos de vegetación, desde el bosque tropical caducifolio, matorral bajo espinoso, bosque de encino y bosque de pino-encino, hasta el bosque de coníferas, incluyendo los pastizales naturales y los derivados del manejo antropogénico, en una franja altitudinal que va de 1000 a 3500 m. (Fig. 4). 
La presencia de un gran número de especies en la Sierra del Centro, en la Región de los Valles y Ciénagas, así como en la Sierra Madre del Sur, obedece sin duda a una serie de condiciones que aquí se encuentran: clima, topografía, microambientes, relieve e historia natural. Por otro lado los registros indican una mayor intensidad de colecta para tales comarcas como consecuencia de su ubicación cercana a las principales vías de comunicación o alrededor de centros de población. Asimismo es muy probable que la existencia de estas plantas se vea favorecida en ambientes de clima templado, que son los predominantes en las regiones antes mencionadas. Por otro lado, la escasa representación del género en la región de Tierra Caliente y su ausencia en la región de la Costa, podría deberse en parte a la falta de exploración y colecta en estas zonas, así como de vías de comunicación y de seguridad en las mismas (Cuadro 1).

Cuadro 1. Distribución de las especies de Eryngium en las regiones naturales de Michoacán.

\begin{tabular}{lccccc}
\hline Especie & $\begin{array}{c}\text { Región de } \\
\text { los Valles } \\
\text { y Ciénagas }\end{array}$ & $\begin{array}{c}\text { Región de } \\
\text { la Sierra } \\
\text { del Centro }\end{array}$ & $\begin{array}{c}\text { Región de } \\
\text { la Tierra } \\
\text { Caliente }\end{array}$ & $\begin{array}{c}\text { Región de la } \\
\text { Sierra Madre } \\
\text { del Sur }\end{array}$ & $\begin{array}{c}\text { Región } \\
\text { de la } \\
\text { Costa }\end{array}$ \\
\hline Eryngium alternatum & - & $\mathrm{X}$ & - & - & - \\
Eryngium beecheyanum & $\mathrm{X}$ & $\mathrm{X}$ & $\mathrm{X}$ & $\mathrm{X}$ & - \\
Eryngium bonplandii & $\mathrm{X}$ & $\mathrm{X}$ & - & $\mathrm{X}$ & - \\
Eryngium carlinae & $\mathrm{X}$ & $\mathrm{X}$ & - & - & - \\
Eryngium columnare & - & $\mathrm{X}$ & - & - & - \\
Eryngium cervantesii & $\mathrm{X}$ & $\mathrm{X}$ & - & - & - \\
Eryngium comosum & $\mathrm{X}$ & $\mathrm{X}$ & - & - & - \\
Eryngium cymosum & - & $\mathrm{X}$ & - & - & - \\
Eryngium ghiesbreghtii & - & $\mathrm{X}$ & $\mathrm{X}$ & $\mathrm{X}$ & - \\
Eryngium gracile & - & $\mathrm{X}$ & - & $\mathrm{X}$ & - \\
Eryngium heterophyllum & $\mathrm{X}$ & - & - & - & - \\
Eryngium longifolium & $\mathrm{X}$ & $\mathrm{X}$ & - & $\mathrm{X}$ & - \\
Eryngium mexiae & $\mathrm{X}$ & $\mathrm{X}$ & - & - & - \\
Eryngium mexicanum & $\mathrm{X}$ & $\mathrm{X}$ & - & - & \\
Eryngium monocephalum & - & $\mathrm{X}$ & - & - & - \\
Eryngium phyteumae & $\mathrm{X}$ & $\mathrm{X}$ & - & - & - \\
Eryngium proteaeflorum & - & $\mathrm{X}$ & - & - & - \\
Eryngium serratum & $\mathrm{X}$ & $\mathrm{X}$ & - & - & - \\
Eryngium sparganophyllum & - & $\mathrm{X}$ & - & - & - \\
Eryngium spiculosum & - & - & $\mathrm{X}$ & - & - \\
Eryngium subacaule & - & $\mathrm{X}$ & - & - & - \\
\hline
\end{tabular}




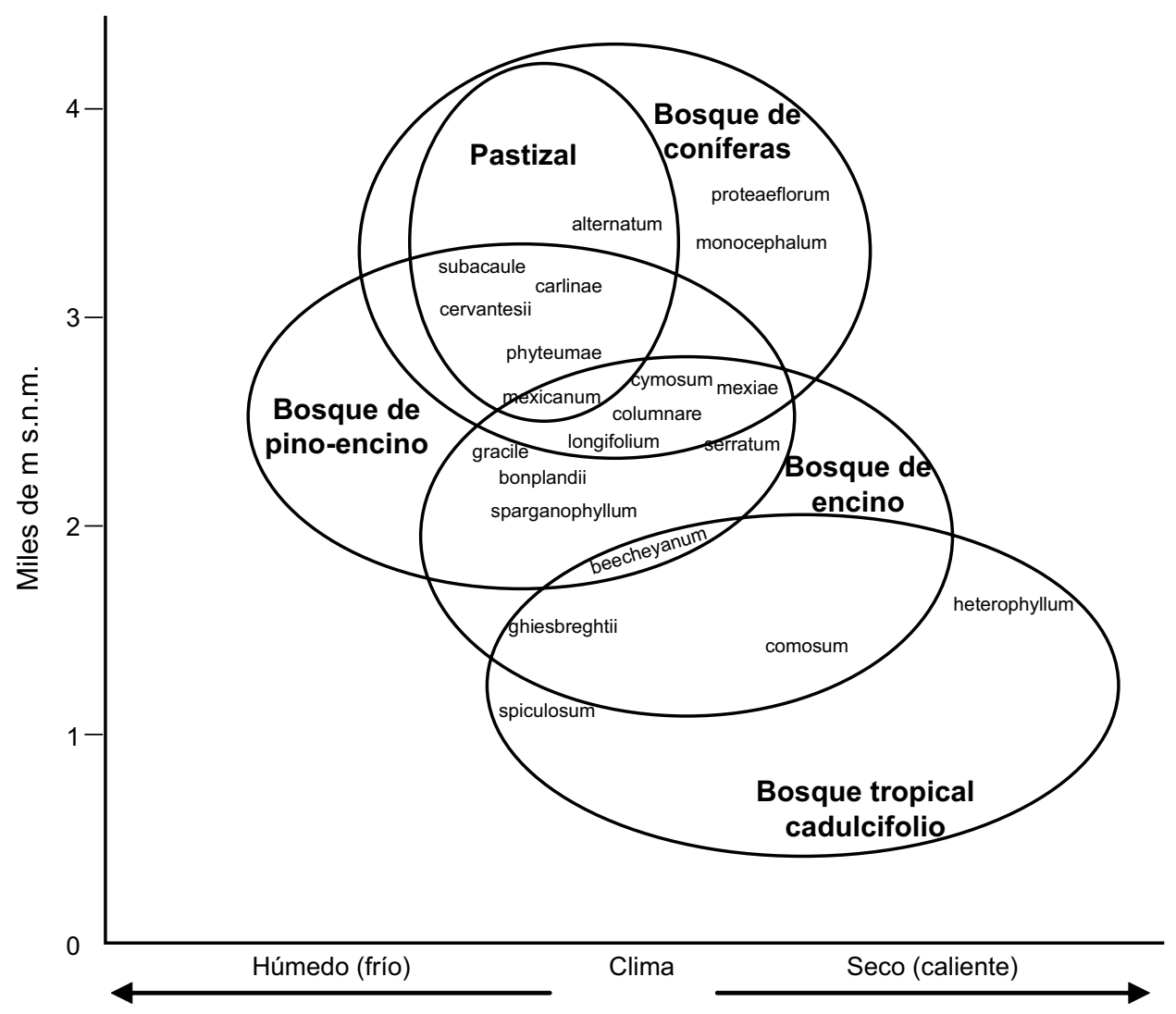

Fig. 4. Diagrama sobre las tendencias de agrupación y distribución de las especies del género Eryngium en los diferentes ecosistemas en que se desarrollan con respecto a la altitud y al clima en el estado de Michoacán en base a literatura consultada, datos de material de herbario y observaciones en campo

Datos de frecuencia y abundancia

Algunas especies de Eryngium forman poblaciones pequeñas y restringidas generalmente a unas cuantas localidades, con la presencia de individuos aislados, destacando entre ellas las de porte robusto y amacollado como E. alternatum, $E$. cymosum, E. columnare, E. longifolium, E. proteaeflorum, E. mexiae y E. sparganophyllum. De éstas E. alternatum frecuentemente se ve favorecida por el disturbio (Fig. 5). Otras se observan en colonias abiertas de individuos que crecen muy cercanos entre sí. Tal es el caso de Eryngium bonplandii, E. ghiesbreghtii, E. gracile, E. heterophyllum, E. serratum y E. comosum. Otras más constituyen colonias de 
García-Ruiz: El género Eryngium en Michoacán, México
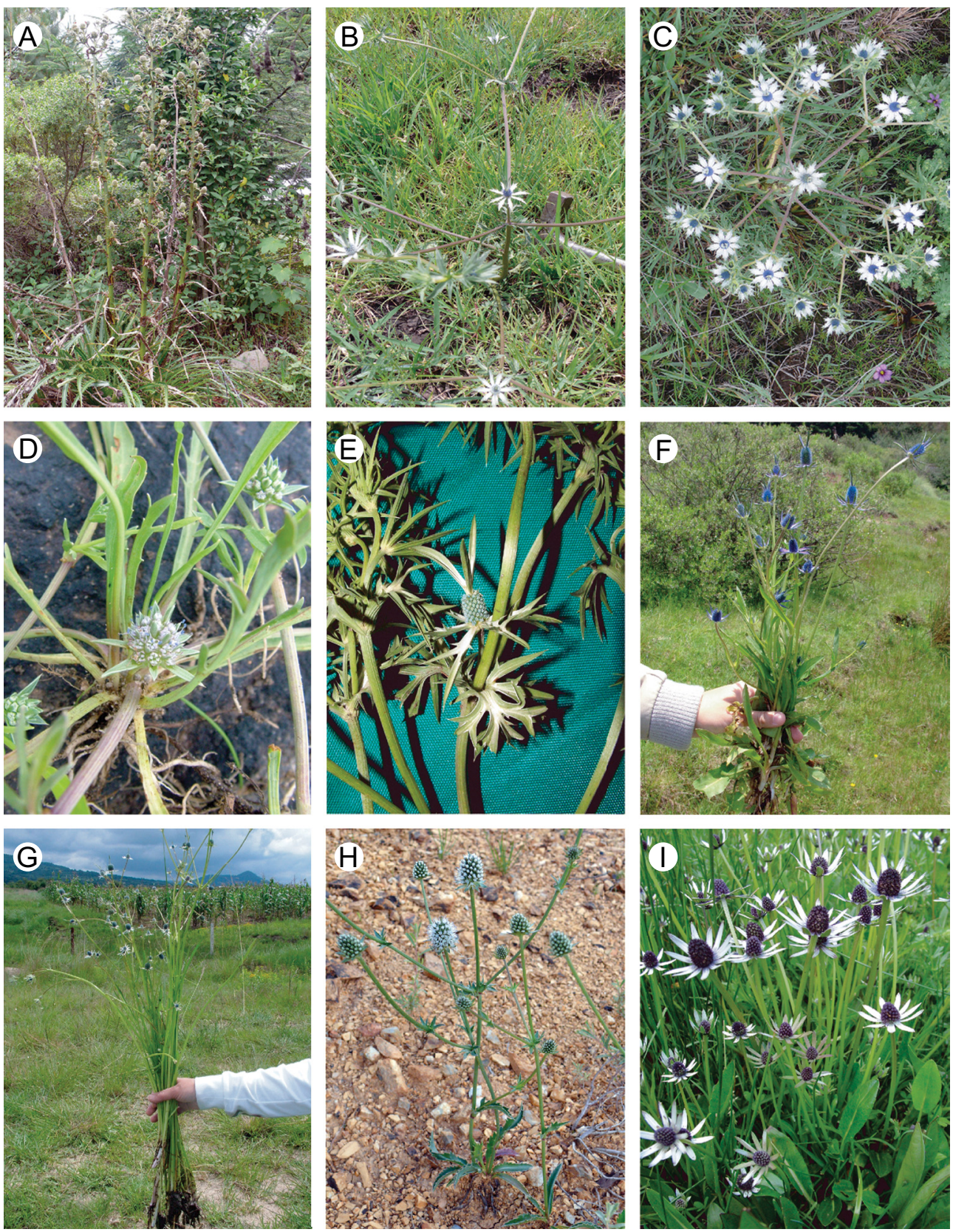

Fig. 5. Hábito de algunas especies de Eryngium de Michoacán: A. E. alternatum; B. E. beecheyanum; C. E. carlinae; D. E. cervantesii; E. E. comosum; F. E. phyteumae; G. E. mexicanum; H. E. serratum; I. E. subacaule. 
numerosos individuos como Eryngium beecheyanum, E. carlinae, E. mexicanum, E. phyteumae, E. spiculosum, E. subacaule y E. cervantesii; esta última produce individuos nuevos a partir de estolones.

La especie más común en el estado es Eryngium beecheyanum. Son también abundantes Eryngium mexiae, E. longifolium y E. serratum, y menos comunes $E$. subacaule, E. mexicanum, E. phyteumae, E. cervantesii, E. cymosum, E. bonplandii, E. ghiesbreghtii y E. gracile.

De E. columnare, E. comosum, E. heterophyllum, E. monocephalum, E. proteaeflorum, E. sparganophyllum y E. spiculosum se obtuvieron muy pocos registros.

Datos sobre polinizadores

En Eryngium la polinización es entomófila. Se observaron abejas, avispas, hormigas y diversos tipos de moscas visitando las inflorescencias. E. proteaeflorum presenta la inflorescencia de mayor tamaño y tiene un característico olor a materia fecal, muy probablemente es polinizada por moscas. E. alternatum es menos fétida que la anterior y es visitada por bastantes y variados insectos (Fig. 6). En E. carlinae, E. phyteumae y E. subacaule, también se observaron insectos.

Morfología de los mericarpos

Con respecto a la variación morfológica de la ornamentación que presentan los frutos de las especies de Eryngium de Michoacán, se infiere que ésta se vincula con diferencias en el número cromosómico como lo han encontrado Bell y Constance $(1960,1966)$ y Constance et al. $(1971,1976)$. Las especies de la serie aneuploide, o "grupo mexicano" (hojas con venación reticulada) presentan escamas, vesículas o papilas generalmente redondeadas, de diversas formas y tamaño y números cromosómicos $x=6,7$ y 8 . A su vez las de la serie poliploide o "grupo monocotyloidea" (hojas de venación paralela) generalmente muestran la cara dorsal de los frutos lisa o desnuda, encontrándose sólo algunas papilas planas, cónicas alargadas en las costillas laterales y ocasionalmente en la base de los segmentos del cáliz de algunas especies, muy diferentes a las del primer grupo y presentan números cromosómicos $x=16,24,32,40$ y 48 .

En las especies de la serie aneuploide o "grupo mexicano" el parecido de la ornamentación que presentan permite reconocer varios grupos, el primero conformado por E. beecheyanum, E. carlinae y E. heterophyllum; en el segundo están E. comosum y E. ghiesbreghtii; un tercero lo constituyen E. cervantesii, E. phyteumae y E. serratum; el cuarto $E$. bonplandii y E. gracile; y sin parecido aparente entre las demás especies de la serie, con ornamentación muy particular, están E. mexicanum, E. spiculosum 
García-Ruiz: El género Eryngium en Michoacán, México
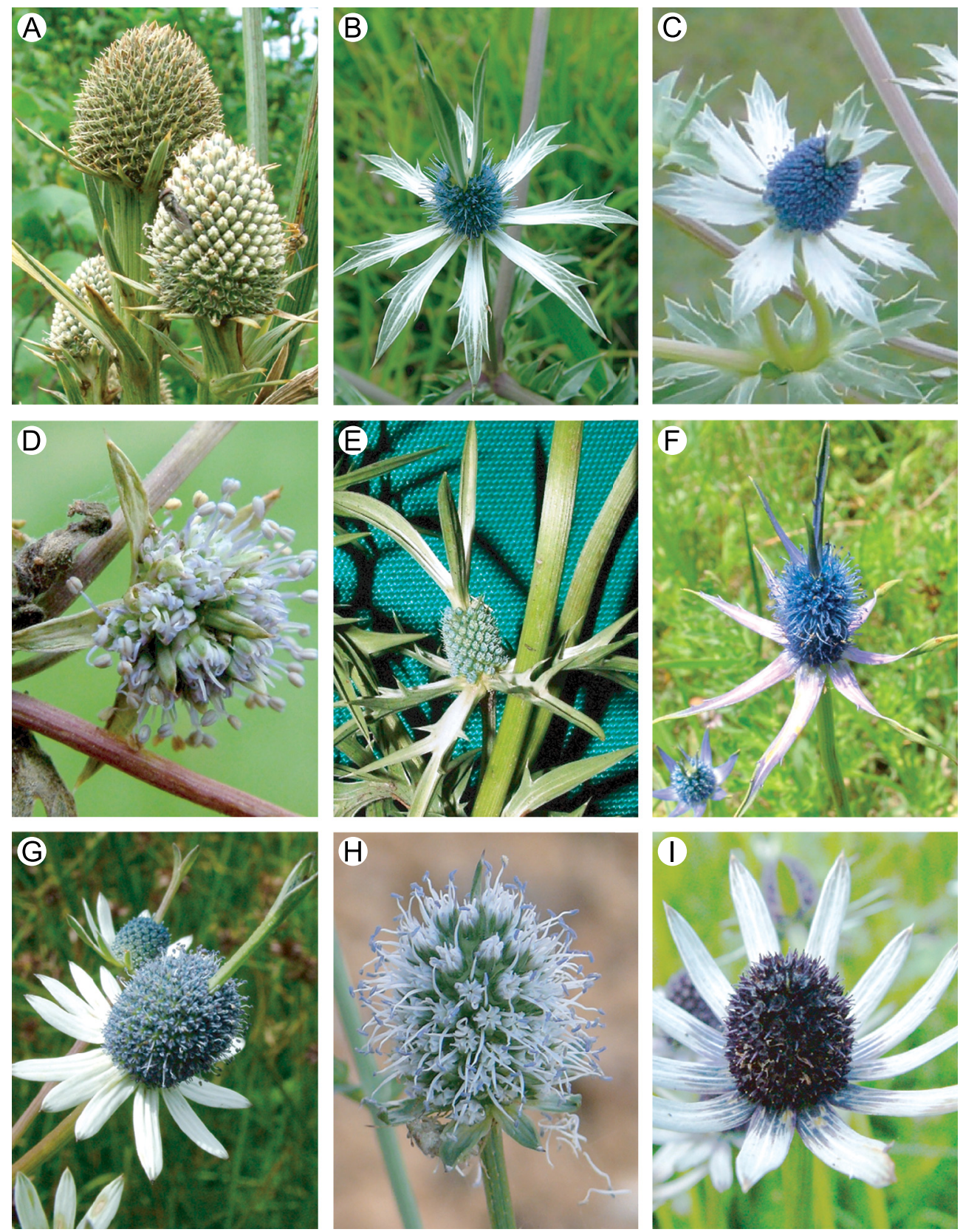

Fig. 6. Inflorescencias de algunas especies de Eryngium de Michoacán: A. E. alternatum; B. E. beecheyanum; C. E. carlinae; D. E. cervantesii; E. E. comosum; F. E. phyteumae; G. E. mexicanum; H. E. serratum; I. E. subacaule. 
y E. subacaule. Por la ornamentación setiforme de las papilas o vesículas que presenta E. spiculosum, éste podría considerarse muy particular dentro de la serie (Fig. 7).

Entre las especies de la serie poliploide o "grupo monocotyloidea", las que tienen cierto parecido entre sí son E. alternatum y E. proteaeflorum; así como $E$. cymosum, E. longifolium y E. mexiae; por su parte en E. columnare la superficie de los mericarpios es lisa, ya que no presenta papilas en la superficie dorsal del fruto. La observación de la morfología en los mericarpos de material escasamente disponible de E. monocephalum lo relacionan con E. alternatum y E. proteaeflorum.

\section{Problemas taxonómicos}

No ha sido fácil la determinación y separación de algunos individuos de los diferentes grupos o complejos que integran este género. Un conjunto particularmente problemático es el que forman Eryngium heterophyllum-beecheyanum-carlinae, ya que el parecido morfológico, sobre todo en estados juveniles de los individuos, así como la presencia de hojas arrosetadas, algo espinosas y de un tallo erecto o cabezuelas con coma, provoca cierta confusión. Algo similar ocurre con el grupo de Eryngium cymosum-pectinatum-mexiae, en el cual es difícil distinguir claramente a las especies, sobre todo en plantas con las inflorescencias inmaduras (Constance, 1977). Entre los caracteres que fueron de utilidad para el reconocimiento de los taxones se encuentran principalmente la ornamentación de las vesículas, papilas o escamas externas del fruto, la morfología y la disposición de las hojas basales, la inflorescencia y las características de las brácteas y el coma, así como el ambiente en el que crecen las plantas y los datos fenológicos respectivos. Sin duda el uso de herramientas actuales como los métodos de aislamiento del ADN de las especies y marcaje molecular (Calviño y Downie, 2007; Calviño et al., 2008) y de secuenciación (Kadereit et al., 2008), contribuyen al mejor conocimiento del grupo.

Nombres o especies excluidas

Los siguientes nombres o taxa citados por varios autores han sido excluidos del presente trabajo.

Eryngium crassisquamosum Hemsl., citada por Rodríguez-Jiménez y Espinosa-Garduño (1996), de la colecta de R. King y Soderstrom 5172 (MEXU, UC), que se identificó como E. mexiae Constance (Constance, 1980).

Eryngium galeottii Hemsl., citada por Rodríguez-Jiménez y Espinosa-Garduño (1996), de la colecta de G. B. Hinton et al. 15380 (ENCB), misma que corresponde a E. bonplandii. 

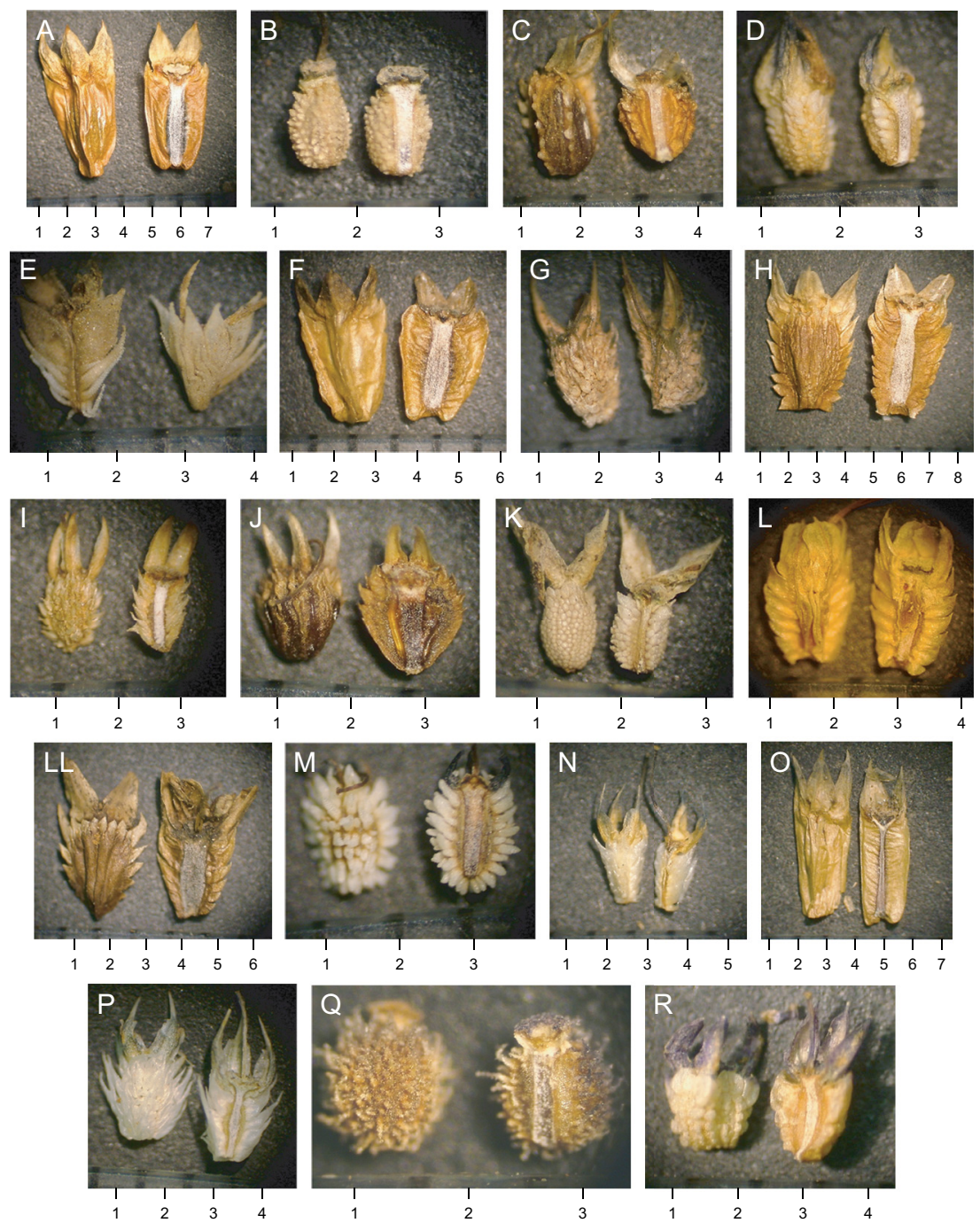

Fig. 7. Frutos de algunas especies de Eryngium de Michoacán. Para cada especie se muestra del lado derecho la cara ventral y del lado izquierdo la cara dorsal. Nótese la evidente presencia de papílas en las especies que tienen hojas de nervación reticulada y la ausencia en las que poseen hojas con nervación paralela. A. E. alternatum (I.G. 3698); B. E. beecheyanum (I.G. 2201); C. E. bonplandii (I.G. 3010); D. E. carlinae (I.G. 3559); E. E. cervantesii (I.G. 3236); F. E. columnare (I.G. 3526); G. E. comosum (I.G. 3538); H. E. cymosum (I.G. 3546); I. E. ghiesbreghtii (I.G. 3364); J. E. gracile (I.G. 3064); K. E. heterophyllum (I.G. 3655); L. E. longifolium (I.G. 3059); LL. E. mexiae (I.G. 3454); M. E. mexicanum (I.G. 3544); N. E. phyteumae (I.G. 3229); O. E. proteaeflorum (I.G. 3661); P. E. serratum (I.G. 3536); Q. E. spiculosum (I.G. 3402); R. E. subacaule (I.G. 3558). 
Eryngium globosum Hemsl., citada por Mathias y Constante (1941, 1945), y por Rodríguez-Jiménez y Espinosa-Garduño (1996) con base en la colecta de $R$. King y Soderstrom 5013, misma que se considera perteneciente a E. mexiae.

Eryngium gramineum F. Delaroche, reportada por Rodríguez-Jiménez y Espinosa-Garduño (1996), de la colecta de V. M. Huerta 393 (EBUM, IEB), que se identifica como $E$. longifolium. Otro ejemplar citado por las mismas autoras con ese nombre E. García et al. 3372 (IEB), corresponde a E. gracile.

Eryngium madrense S. Wats., citado por Rodríguez-Jiménez y EspinosaGarduño (1996), de la colecta de $J$. M. Escobedo 496 (ENCB), corresponde a $E$. mexicanum.

Eryngium palmeri Hemsl., citado por Rodríguez-Jiménez y Espinosa-Garduño (1996), de la colecta de S. Zamudio 6007 (IEB), se determina como E.cymosum.

Eryngium pectinatum C. Presl, citado por Rodríguez-Jiménez y EspinosaGarduño (1996), de las colectas de H. Díaz 1854 (ENCB, IEB), y E. Carranza 366 (EBUM); al parecer se trata de E. mexiae.

Eryngium pilularioides Hemsl. \& Rose, mencionada por Constance (L. Constance, com. pers. 1988) de una colecta de G. Arsène en octubre de 1890 para la Loma Santa María, Morelia, no fue localizada. Tampoco se observó el material de herbario citado para este sitio. Posiblemente haya sido citada erróneamente o se encuentre ya desaparecida de la flora de la entidad.

Eryngium purpusii Hemsl. \& Rose, citado por Rodríguez-Jiménez y Espinosa-Garduño (1996), de la colecta sin número de la exploración Idaho (MEXU); corresponde a E. mexiae.

\section{AGRADECIMIENTOS}

Agradezco a los Drs. Jerzy Rzedowski y Sergio Zamudio por la revisión crítica del manuscrito y sugerencias. Expreso mi gratitud al Dr. Lincoln Constance (q.e.p.d.) por su auxilio en identificaciones, literatura y valiosos comentarios sobre este género. Estoy agradecido con Andrés García Escamilla (q.e.p.d), Ma. Eustacia García Ruiz y Yolanda Hernández por el apoyo durante el trabajo de campo, también con Melissa, Karen Angelina y Mariana García Hernández por su compañía en la etapa final de colectas de campo. A Israel Soto por su auxilio en la revisión de herbario. Del CIIDIR Michoacán agradezco a Elizabeth Gómez Magallón por su auxilio en la captura inicial del manuscrito, a Jaime Nava Velázquez por su apoyo en salidas de campo y a Fabián Villalpando Barragán por su ayuda en el manejo de las imáge- 
nes. Asimismo a los encargados de los herbarios consultados, agradezco el acceso a sus colecciones. También expreso mi gratitud y reconocimiento a los revisores anónimos quienes aportaron varias e importantes ideas para mejorar el trabajo. A Rosa María Murillo por la revisión y sus valiosos comentarios durante la fase inicial de este trabajo. A la La Comisión de Operación y Fomento de Actividades (COFAA) del Instituto Politécnico Nacional por apoyar esta investigación.

\section{LITERATURA CITADA}

Bell, C. R. y L. Constance. 1960. Chromosome numbers in Umbelliferae. II. Amer. J. Bot. 47: 24-32.

Bell, C. R. y L. Constance. 1966. Chromosome numbers in Umbelliferae. III. Amer. J. Bot. 53: 512-520.

Calviño, I. C. y S. R. Downie. 2007. Circumscription and phylogeny of Apiaceae subfamily Saniculoideae based on chloroplast DNA sequences. Mol. Phyl. Evol. 44: 175-191.

Calviño, I. C., S. G. Martínez y S. R. Downie. 2008. The evolutionary history of Eryngium (Apiaceae, Saniculoideae): rapid radiations, long distance dispersal, and hybridizations. Mol. Phyl. Evol. 46: 1129-1150.

Constance, L. Chuang T-I y C. R. Bell. 1971. Chromosome numbers in Umbelliferae. IV. Amer. J. Bot. 58: 577-587.

Constance, L. Chuang T-I y C. R. Bell. 1976. Chromosome numbers in Umbelliferae. V. Amer. J. Bot. 63: 608-625.

Constance, L. 1977. Some problems in New World Eryngium. In: Cauwet Marc, A. M. y J. Carbonier (eds.). Les Ombellifères: contributions pluridisciplinairies à la systématique. Monogr. Syst. Bot., Mo. Bot Gard. 6: 7-19.

Constance, L. 1980. Four new species of Eryngium (Umbelliferae) from Mexico. Brittonia 32: $118-127$.

Correa, P. G. 1974. Geografía del estado de Michoacán. Geografía física. Tomo I. Gobierno del Estado de Michoacán. Morelia, México. 454 pp.

Coulter, M. J. y J. N. Rose. 1900. A synopsis of Mexican and Central American Umbelliferae. Proc. Natl. Acad. Sci. 1: 111-159.

García, E. 1988. Modificaciones al sistema de clasificación climática de Köppen (para adaptarlo a las condiciones de la República Mexicana). 4a ed. Instituto de Geografía, Universidad Nacional Autónoma de México. México, D.F., México. 217 pp.

García, R. I., R. E. Flores R. y J. Nava V. 1991. Estudio florístico del noroeste de Michoacán. Centro Interdisciplinario de Investigación para el Desarrollo Integral Regional, Unidad Michoacán. Informe Técnico. Jiquilpan, México. 121 pp.

Guevara, F. F. 1989. Los factores físico-geográficos. In: Florescano, E. (coord.). Historia general de Michoacán Vol. I. Gobierno del Estado de Michoacán, Instituto Michoacano de Cultura. Morelia, México. pp. 9-33. 
Heywood, V. H. 1978. Flowering plants of the world. Oxford University Press. Oxford., UK. pp. 219-221.

Hiroe, M. 1979. Umbelliferae of the world. Botanical Institute, Kyoto University. Kyoto, Japón. pp.1763-1882

Kadereit, W. J., M. Repplinger, N. Schmalz, C. H. Uhink y A. Wörz. 2008. The phylogeny and biogeography of Apiaceae subf. Saniculoideae tribe Saniculeae: from south to north and south again. Taxon 57: 365-382.

Leavenworth, C. W. 1946. A preliminary study of the vegetation of the region between Cerro Tancitaro and the Rio Tepalcatepec, Michoacán, Mexico. Amer. Midl. Nat. 36: 137-206.

Mabberley, J. D. 1997. The plant-book. 2nd ed. Cambridge University Press. Cambridge, UK. 858 pp.

Martínez, M. y E. Matuda. 1979. Flora del Estado de México. Vol. II. Gobierno del Estado de México. Toluca, México. pp. 322-372.

Mathias, M. E. 1965. Distribution patterns of certain Umbelliferae Ann. Missouri Bot. Gard. 52: 387-398.

Mathias, M. E. y L. Constance. 1941. A synopsis of the North American species of Eryngium. Amer. Midl. Nat. 25: 361-387.

Mathias, M. E. y L. Constance. 1945. Eryngium. N. Amer. Fl. 28(2): 261-292.

Miramontes, F. F. 1936. Geografía económico agrícola del Estado de Michoacán. Vol. I. Dirección de Economía Rural, Secretaría de Agricultura y Fomento.. México, D.F., México. pp. 94-99.

Rodríguez-Jiménez, L. S. y J. Espinosa-Garduño. 1996. Listado florístico del Estado de Michoacán. Sección V (Angiospermae: Najadaceae-Zygophyllaceae). Flora del Bajío y de Regiones Adyacentes XV: 294-303.

Rzedowski, G. C. de, J. Rzedowski y colaboradores. 2001. Flora fanerogámica del Valle de México. 2a. ed. Instituto de Ecología, A.C. y Comisión Nacional para el Conocimiento y Uso de la Biodiversidad. Pátzcuaro, México. pp. 506-511.

Turmel, J. M. 1948. Répartition géographique des Eryngium. I. Ancien Monde. Bull. Mus. Hist. Nat. 20: 395-401.

Turmel, J. M. 1949. Répartition géographique des Eryngium. II. Nouveau Monde. Bull. Mus. Hist. Nat. 21: 120-131.

Wolff, H. 1913. Eryngium. In: Engler, A. (ed.). Umbelliferae-Saniculoideae. Das Pflanzenreich IV (228): 106-271.

Wörz, A. 2005. A new subgeneric classification of the genus Eryngium L. (Apiaceae, Saniculoideae). Bot. Jahrb. Syst. 126: 253-259. 